\title{
Projected Response of Tropical Cyclone Intensity and Intensification in a Global Climate Model
}

\author{
KIERAN BHATIA \\ Princeton University, and NOAA/Geophysical Fluid Dynamics Laboratory, Princeton, New Jersey \\ GABRIEL VECCHI \\ Geosciences Department, and Princeton Environmental Institute, Princeton University, Princeton, New Jersey \\ HiROYUKI MURAKAMI \\ Princeton University, and NOAA/Geophysical Fluid Dynamics Laboratory, Princeton, New Jersey \\ SETH UNDERWOOD \\ NOAA/Geophysical Fluid Dynamics Laboratory, Princeton, New Jersey \\ JAMES KOSSIN \\ NOAA/National Centers for Environmental Information, Center for Weather and Climate, University of \\ Wisconsin-Madison, Madison, Wisconsin
}

(Manuscript received 27 December 2017, in final form 15 July 2018)

\begin{abstract}
As one of the first global coupled climate models to simulate and predict category 4 and 5 (Saffir-Simpson scale) tropical cyclones (TCs) and their interannual variations, the High-Resolution Forecast-Oriented Low Ocean Resolution (HiFLOR) model at the Geophysical Fluid Dynamics Laboratory (GFDL) represents a novel source of insight on how the entire TC intensification distribution could be transformed because of climate change. In this study, three 70-yr HiFLOR experiments are performed to identify the effects of climate change on TC intensity and intensification. For each of the experiments, sea surface temperature (SST) is nudged to different climatological targets and atmospheric radiative forcing is specified, allowing us to explore the sensitivity of TCs to these conditions. First, a control experiment, which uses prescribed climatological ocean and radiative forcing based on observations during the years 1986-2005, is compared to two observational records and evaluated for its ability to capture the mean TC behavior during these years. The simulated intensification distributions as well as the percentage of TCs that become major hurricanes show similarities with observations. The control experiment is then compared to two twenty-first-century experiments, in which the climatological SSTs from the control experiment are perturbed by multimodel projected SST anomalies and atmospheric radiative forcing from either 2016-35 or 2081-2100 (RCP4.5 scenario). The frequency, intensity, and intensification distribution of TCs all shift to higher values as the twenty-first century progresses. HiFLOR's unique response to climate change and fidelity in simulating the present climate lays the groundwork for future studies involving models of this type.
\end{abstract}

\section{Introduction}

The ability of society to adapt to future climate change could be enhanced by furthering research on how the most intense tropical cyclones (TCs) will respond to climate change. Between 1900 and 2005, major hurricanes

Corresponding author: Kieran T. Bhatia, kbhatia@princeton.edu [wind speeds greater than $95 \mathrm{kt}\left(1 \mathrm{kt}=0.5144 \mathrm{~m} \mathrm{~s}^{-1}\right)$; categories 3-5 on the Saffir-Simpson scale] accounted for $85 \%$ of the total damage of all storms in the United States (Pielke et al. 2008). A recent study by Lee et al. (2016) highlighted that almost all of these intense tropical cyclones undergo rapid intensification (RI; commonly defined as the 95 th percentile of all $24-\mathrm{h}$ intensity changes) during their lifetime. RI events are 
responsible for intensity forecasts with the highest errors, and hurricanes that rapidly intensify before landfall cause a majority of the fatalities and damage from TCs (Emanuel 2017). Therefore, researching whether the frequency of major hurricanes and their associated intensification rates are likely to change during the twenty-first century is critical for the development of adaptation strategies and resiliency efforts for coastal cities.

Atmospheric general circulation models (AGCMs), coupled atmosphere-ocean general circulation models (CGCMs), dynamical downscaling, and statisticaldynamical downscaling are four different modeling techniques that have successfully resolved the entire intensity distribution of TCs. As a result, they can all serve as tools for exploring how climate change will influence the frequency and intensity of nature's strongest storms. In recent years, the horizontal resolution in AGCMs has rapidly improved, enabling multidecadal studies to skillfully reproduce several facets of the observed TC climatology, including geographical, seasonal, and interannual variations (Oouchi et al. 2006; Murakami et al. 2012; Zhao et al. 2009; Manganello et al. 2012; Chen and Lin 2011, 2013; Rathmann et al. 2014; Bacmeister et al. 2014; Shaevitz et al. 2014; Kodama et al. 2015; Walsh et al. 2016; Yamada et al. 2017). The impressive retrospective performance of AGCMs suggests their modeled future TC behavior is also realistic. Consequently, AGCMs are used to produce long-range forecasts of TCs in different climate change scenarios (Yamada et al. 2010; Murakami et al. 2012; Manganello et al. 2014; Bacmeister et al. 2018; Wehner et al. 2015). However, it is important to acknowledge that AGCMs omit critical dynamical processes that occur at the airsea interface. AGCMs do not capture wind-induced ocean mixing, which is sizable under major TCs (e.g., Huang et al. 2017; Lin et al. 2013; Lloyd and Vecchi 2011). Accurate representation of the cooled waters that are left in the wake of intense TCs is important, because they can limit TC intensification and genesis (Schade and Emanuel 1999; Bender and Ginis 2000; Lin et al. 2013).

CGCMs represent an appealing alternative because they explicitly resolve physical processes and their nonlinear interactions on a variety of time and spatial scales in the ocean, atmosphere, and the oceanatmosphere interface. CGCMs are arguably the most seamless approach to projecting climate change effects on TCs, but they require tremendous computational resources (e.g., Small et al. 2014) and often have significant biases in the mean state that decrease the likelihood of accurate future projections. For these reasons, lower-resolution CGCMs and AGCMs are often paired with downscaling techniques to reproduce the strongest TCs.

To analyze how TCs will respond to different climate conditions, dynamical downscaling inputs the TC vortex structure and the environmental conditions of CGCMs or AGCMs into a higher-resolution regional model (first utilized by Knutson et al. 1998 and Knutson and Tuleya 2004). Statistical-dynamical downscaling is another inexpensive method for extracting information from climate models and was first discussed by Emanuel et al. (2006) and Emanuel (2006). Using this approach, TCs are randomly seeded before a beta-and-advection model and coupled air-sea model (Coupled Hurricane Prediction Intensity Prediction System) respectively control the track and intensity evolutions of TCs. Although dynamical and statistical-dynamical downscaling techniques were able to reproduce past TC activity very well (Knutson et al. 2007; Emanuel et al. 2008), the assumptions implicit in these techniques introduce additional uncertainties into their TC projections.

Dynamical and statistical-dynamical downscaling studies require the use of regional models, which also struggle at simulating strong hurricanes. In these models, resolution constraints and/or convection moving through model domains are large sources of error that are further exacerbated by the biases in the parent global climate model (Camargo and Wing 2016). In both dynamical and statistical-dynamical downscaling, ocean coupling is often omitted in the regional domain (Murakami et al. 2012) and almost always in the global domain (e.g., Knutson et al. 2015; Korty et al. 2017). Even in downscaling frameworks that include ocean coupling, cold wakes generated by storms do not feed back on the large-scale environment in the model. Meanwhile, high-resolution CGCMs can simulate significant cold wakes underneath strong TCs (Murakami et al. 2015; Scoccimarro et al. 2017; McClean et al. 2011). Statistical-dynamical downscaling also does not consider how the climatology of initial disturbances evolves with climate change, how storm intensity and size affect movement, and how extratropical interactions impact TC development (Korty et al. 2017).

In this study, we bypass the mentioned uncertainties associated with AGCMs and downscaling techniques by using the Geophysical Fluid Dynamics Laboratory (GFDL) High-Resolution Forecast-Oriented Low Ocean Resolution (HiFLOR) model, a state-of-the-art CGCM, to produce climate projections of TC activity. HiFLOR (Murakami et al. 2015) is one of the three CGCMs [Centro Euro-Mediterraneo sui Cambiamenti Climatici Climate Model (CMCC-CM2-VHR) developed by Scoccimarro et al. (2017); Community Earth System Model (CESM) developed by Small et al. 
(2014)] that has explicitly represented category 4 and 5 TCs (wind speeds greater than $112 \mathrm{kt}$ ). Previous studies within the HiFLOR framework have showed that HiFLOR reproduces the spatial and intensity distribution of the TC climatology with accuracy comparable to experiments involving high-resolution AGCMs, dynamical downscaling, and statistical downscaling experiments (Murakami et al. 2015; Zhang et al. 2016; cf. studies in review by Knutson et al. 2010). Additionally, Murakami et al. (2015, 2016) and Zhang et al. (2016) have demonstrated that HiFLOR can skillfully predict inter- and intra-annual variations in hurricane and major hurricane frequency.

Motivated by HiFLOR's success at capturing TC intensity behavior and structure, this study explores whether HiFLOR can also recover the intensification distribution of TCs and how climate change can affect that distribution. Three 70-yr HiFLOR experiments (introduced in van der Wiel et al. 2017) are performed to identify the effects of climate change on TC intensity characteristics. The "control" (CTL) experiment aims to represent the observed climate during the period 1986-2005, while the "early" and "late" experiments respectively project the climate during 2016-35 and 2081-2100 under the RCP4.5 scenario. Two observational datasets are used to validate the HiFLOR CTL experiment: the International Best Track Archive for Climate Stewardship (IBTrACS) produced by the National Hurricane Center (NHC) and the Joint Typhoon Warming Center (JTWC) (Knapp et al. 2010), and the advanced Dvorak technique-Hurricane Satellite-B1 (ADT-HURSAT) (Kossin et al. 2013).

Section 2 provides more details on the methodology of each experiment along with a description of the HiFLOR model and observational data sources. The next two sections are composed of the analyses of the HiFLOR experiments. We first compare the mean global TC intensity behavior observed for the years 1986-2005 to the HiFLOR CTL simulation, and then our analysis pivots toward understanding how the intensity and intensification distribution of TCs will evolve during the twenty-first century. The final section of the paper includes a summary of the results and a discussion of future research inspired by this study.

\section{Data and methodology}

\section{a. HiFLOR model and experiments}

HiFLOR is composed of a high-resolution atmospheric/ land model $\left(0.25^{\circ} \times 0.25^{\circ}\right)$ coupled to a low-resolution oceanic/sea ice model $\left(1^{\circ} \times 1^{\circ}\right.$; Murakami et al. 2015). HiFLOR was developed from the Forecast-Oriented Low Ocean Resolution (FLOR; Vecchi et al. 2014; Jia et al.
2015) model, which contains atmosphere and land elements from the GFDL Climate Model, version 2.5 (CM2.5; Delworth et al. 2012), and ocean and sea ice components based on the GFDL Climate Model, version 2.1 (CM2.1; Delworth et al. 2006; Wittenberg et al. 2006; Gnanadesikan et al. 2006). The dynamical core and physical parameterizations will not be discussed here because they are very similar to FLOR and have been documented elsewhere (Vecchi et al. 2014; Jia et al. 2015; Murakami et al. 2015). TCs are tracked using warm-core temperature, sea level pressure (SLP), and 10-m wind from 6-hourly HiFLOR output. This tracker was developed by Harris et al. (2016) and is applied using the parameter values of Zhang et al. (2016) and Murakami et al. (2015).

HiFLOR was integrated for 70 years in each experiment. SSTs were relaxed to climatological SST values representative of the 20 -yr period of interest. Thus, each of the 70 years has approximately the same SSTs and radiative forcing, which substantially reduces the interannual and decadal variability of the climate system. This experimental setup will not be able to capture the rectified response of climatological TC activity to changes in the interannual or decadal variability of SSTs and radiative forcing. However, we hypothesize that these variations are smaller than the response of climatological TC activity driven by climatological changes in SST-a hypothesis that is supported by fully coupled and nudgedSST experiments in G. Vecchi et al. (2018, manuscript submitted to Climate Dyn.). For the CTL experiment, the prescribed SST target was the monthly varying climatology from the Met Office Hadley Centre Sea Ice and SST dataset (HadISST1.1; Rayner et al. 2003) over the years 1986-2005. The early and late experiments used the same climatological values of SSTs, sea ice, and greenhouse gas concentrations from the CTL experiment plus the projected changes derived from a multimodel mean of 17 CMIP5 models. ${ }^{1}$ These anomalies were based on the RCP4.5 pathway (Van Vuuren et al. 2011).

In each experiment, SST values were relaxed to the prescribed repeating climatology $\left(\mathrm{SST}_{T}\right)$

$$
d \mathrm{SST} / d t=\varphi+1 / \tau\left(\mathrm{SST}_{T}-\mathrm{SST}\right),
$$

in which $\varphi$ is the model-computed tendency for $S S T, \tau$ is the restoring time scale (5 days), and $t$ is time. The restoring time-scale length was carefully selected in Murakami et al. (2015) to be short enough to prevent

\footnotetext{
${ }^{1}$ Models included ACCESS1.0, ACCESS1.3, CanESM2, CCSM4, CMCC-CM, CSIRO Mk3.6.0, GFDL CM3, GFDL-ESM2G, GFDLESM2M, GISS-E2-H, GISS-E2-R, HadGEM2-CC, HadGEM2ES, MIROC-ESM, MIROC-ESM-CHEM, MPI-ESM-LR, and NorESM1-M.
} 
climate drift in the model but long enough to maintain SST cooling effects from a storm's wake. Without $\varphi$, this equation would simply bring the model's SSTs toward the prescribed values with an $e$-folding time scale of $\tau$. The model SST tendency term, which involves advection, mixing, and heat fluxes, enables the SSTs of the model to drift away from $\mathrm{SST}_{T}$ on short and long time scales.

A comparison of the nudged-SST and fully coupled experiments indicates that the nudged-SST framework can capture the response of TCs to radiative forcing (G. Vecchi et al. 2018, manuscript submitted to Climate Dyn.). Meanwhile, the response of TCs to carbon dioxide forcing in HiFLOR is sensitive to the model's underlying SST biases (G. Vecchi et al. 2018, manuscript submitted to Climate Dyn.). These two factors argue in favor of experiments in which the CTL run climatology is kept close to the observed climatology and motivate the experimental setup used here.

\section{b. Observational datasets}

TC intensity observations during 1986-2005 were obtained from IBTrACS and ADT-HURSAT to evaluate the performance of the HiFLOR CTL experiment. IBTrACS is composed of global "best track" data, which are recordings of TC locations and intensities from forecasting agencies across the world. Best track data start as operational estimates of the intensity and track of a TC and are refined at the end of a TC's lifetime with a combination of in situ (e.g., dropsondes, scatterometers, buoys), radar, and satellite measurements. Best track intensity and position estimates are available every $6 \mathrm{~h}$ at the 4 synoptic times $(0000,0600,1200$, and 1800 UTC) and are recorded to the nearest $5 \mathrm{kt}$ and $0.1^{\circ}$ latitude/longitude (Landsea and Franklin 2013). For our analysis, we utilize IBTrACS, v03r09, but only consider data from NHC for the Atlantic and east Pacific and the JTWC for the remainder of the globe. One of the benefits of only using data from these U.S. agencies ${ }^{2}$ is they follow the same definition of maximum winds: the highest 1 -min average at $10-\mathrm{m}$ height over a smooth surface (Harper et al. 2010).

As an official archiving and distribution resource for TC best track data, IBTrACS is the primary dataset used in meteorological studies to validate model performance and compute observational trends in TC metrics. With the exception of the Indian Ocean (which did not gain continuous satellite coverage until 1998), IBTrACS data quality significantly improved in the early 1980s when satellites were deployed globally. Satellites allowed

\footnotetext{
${ }^{2}$ Other forecast agencies have varying definitions of maximum wind speed including different averaging times and methods for deriving those winds.
}

warning centers to employ the Dvorak technique, which is a robust way to estimate TC intensities based on infrared satellites (Kossin et al. 2007; Knapp et al. 2010). As a result, Chu et al. (2002) noted that JTWC's data since 1985 are more reliable than earlier years. Observational tools have continued to evolve to supplement the Dvorak technique, and new geostationary satellites, aerial Doppler radars, and stepped frequency microwave radiometers (SFMRs; Uhlhorn et al. 2007) have recently become available. Therefore, uncertainty in the best track intensity estimates have decreased with time, which introduces temporal heterogeneities in the quality of the data. There are also spatial inconsistencies in observational quality because the number of measurements available in different basins varies considerably.

To assemble a more homogeneous record of TC intensity, Kossin et al. $(2007,2013)$ developed an automated approach called ADT-HURSAT. The creation of ADTHURSAT consists of four main steps. Geostationary satellite imagery is first analyzed from International Satellite Cloud Climatology Project (ISCCP)-B1 data (Knapp and Kossin 2007; Knapp 2008a,b). Then, the data are centered on IBTrACS TCs and subsampled to be both spatially and temporally homogeneous. Finally, a simplified version of the advanced Dvorak technique (Olander and Velden 2007) is used to evaluate the data and determine a maximum TC wind speed. ADT-HURSAT data are produced every $3 \mathrm{~h}$ based on satellite data that has been uniformly subsampled to a horizontal resolution of $8 \mathrm{~km}$, and wind speeds are recorded to the nearest tenth of a Dvorak "T-number" (depending on the current intensity, between 1 and $3 \mathrm{kt}$ ). ADT-HURSAT maintains the same protocol to determine TC intensities but its efforts to stay homogenous prevent it from using the best technology and analysis techniques available. As a result, TC intensities determined with ADT-HURSAT average higher errors than those in the IBTrACS dataset (Kossin et al. 2013; Olander and Velden 2007).

Even with their deficiencies, IBTrACS and ADTHURSAT represent the best options for evaluating the skill of HiFLOR. To maintain consistency when we compare HiFLOR to observations, all data sources are rounded to the nearest $5 \mathrm{kt}$. We only consider TCs that are active for at least $72 \mathrm{~h}$ and exceed wind speeds of $34 \mathrm{kt}$ for at least $36 \mathrm{~h}$, which are identical criteria to the HiFLOR tracker (Murakami et al. 2015). Although we do not have warm-core information (also part of the HiFLOR criteria), the available criteria help us consider TCs of similar longevity and strength to those tracked in HiFLOR. We restrict our analysis sample to only consider cases where the TC center is located over the ocean. When a TC traverses land, intensification processes are controlled by unique physical processes, 


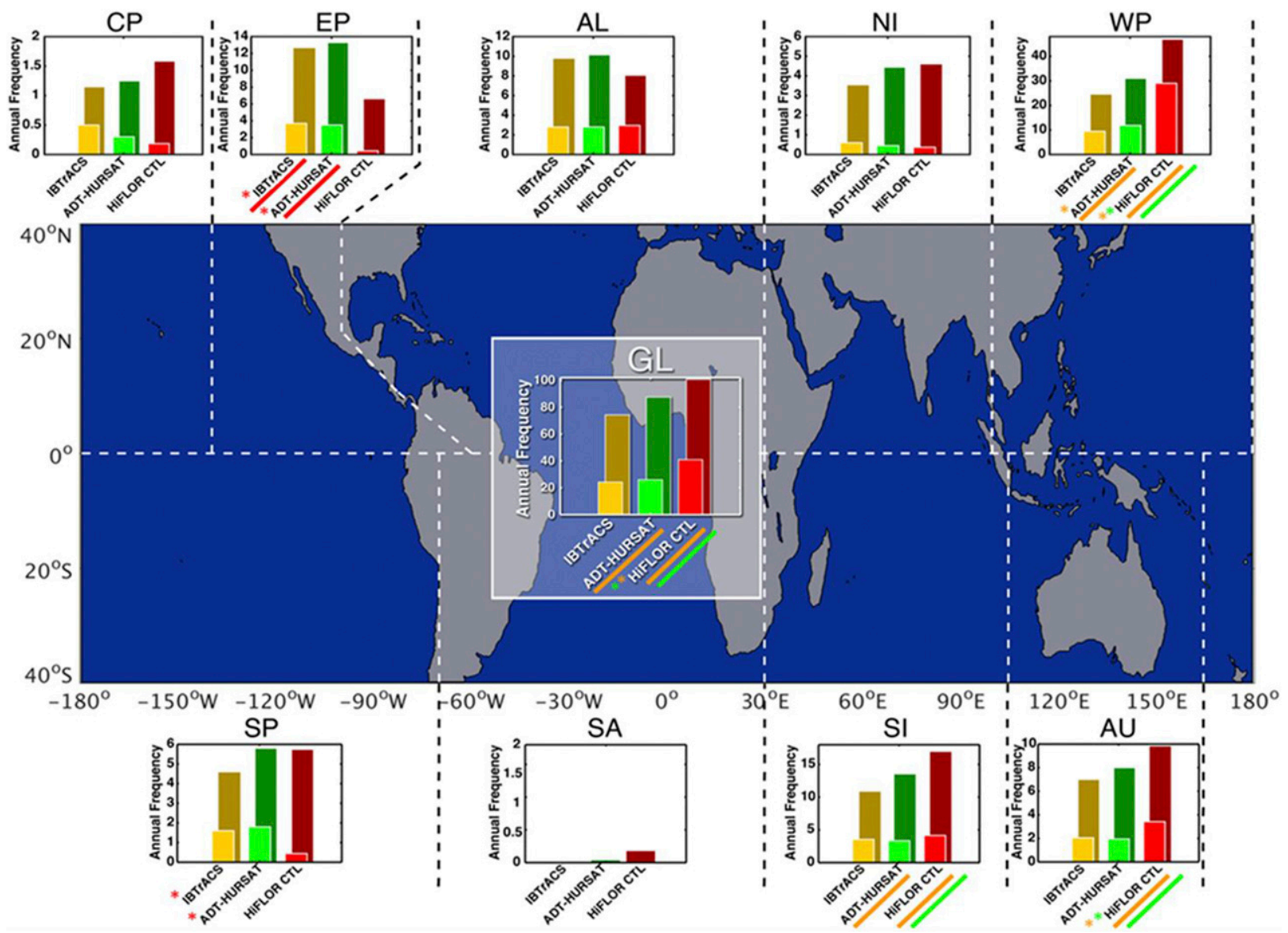

FIG. 1. Histograms represent the annual frequency of TCs (background bars) and major hurricanes (foreground bars) for IBTrACS (yellow), ADT-HURSAT (green), and the HiFLOR CTL simulation (red). The title of each histogram is an abbreviation for the adjacent basin that provides the data to compute the bars. The dashed lines separate the boundaries of the different basins considered in this study. The dataset identifier on the $x$ axis of the histograms is underlined with orange, green, or red if the annual TC count for that dataset is significantly greater than IBTrACS, ADT-HURSAT, or HiFLOR, respectively. An orange, green, or red asterisk on the top-left corner of the dataset identifier indicates the dataset has significantly more major hurricanes than IBTrACS, ADT-HURSAT, or HiFLOR, respectively.

which are poorly resolved in climate models. Additionally, we do not examine TC intensity changes above $40^{\circ}$ latitude because storms often undergo extratropical transition at higher latitudes (Liu et al. 2017). These TCs lose their warm core, and their intensity evolution is controlled by mechanisms that are not typical of tropical systems.

\section{Simulated versus observed tropical cyclone intensity and intensity change}

The mean TC intensity and intensification behavior observed between 1986 and 2005 in IBTrACS and ADTHURSAT is compared to the HiFLOR CTL simulation. Specifically, we examine the realism of the following: the annual frequency of TCs and major hurricanes, the spatial distribution of TCs and major hurricanes, the relationship between lifetime maximum intensity
(LMI) and RI, the probability density of 6- and 24-h wind speed changes, and the spatial distribution of RI rates.

\section{a. Comparing TC intensity statistics}

Figure 1 shows annual totals of TCs (background) and major hurricanes (foreground) for each ocean basin. Histograms are located near the basin that corresponds to the displayed data, and different data sources are represented by each bar. Dashed lines demarcate the boundaries between basins. Two-variable, unpaired $t$ tests (e.g., Wilks 2011) are computed for each basin to establish statistical significance between the datasets. Equation (5.8) from Wilks (2011), adjusted to account for serial correlation between the forecasts [see Wilks's (2011) Eq. (5.12)], is used to determine the Gaussian test statistic $z$, which is converted to a $p$ value. When the $p$ value is less than the significance threshold of 0.05 
for the two-sided test, the difference in the mean TC or major hurricane count is considered statistically significant.

After applying the TC criteria discussed in the previous section, ADT-HURSAT and IBTrACS appear to have slightly different storm totals. This unexpected discrepancy is due to the fact that ADT-HURSAT derives TC locations from the version of IBTrACS that uses data from all agencies and information sources, not just NHC and JTWC (Kossin et al. 2013). There are also TCs in IBTrACS that have position fixes with no associated intensity estimates. For these cases, ADT-HURSAT still provides an intensity estimate because the algorithm only requires the storm position to retrospectively utilize satellite imagery. Therefore, ADT-HURSAT records higher annual storm totals because TCs have longer lifetimes than in IBTrACS.

HiFLOR develops significantly more TCs and major hurricanes than both observational datasets. Globally, each year, HiFLOR approximately averages 13 more storms than ADT-HURSAT and 26 more storms than IBTrACS. In the west Pacific, HiFLOR produces significantly more TCs and major hurricanes than observations. HiFLOR exhibits the opposite behavior in the east Pacific basin, generating far fewer TCs than observations and rarely developing them into strong TCs. HiFLOR most closely resembles ADT-HURSAT and IBTrACS in the Atlantic basin, which is a positive sign for HiFLOR. The Atlantic basin has the most reliable data quality because of the superior observational network in this basin (Kossin et al. 2013).

The Pacific Ocean biases are common features of CGCMs that resolve the strongest TCs (Small et al. 2014; McClean et al. 2011). In Murakami et al. (2015), two types of HiFLOR simulations were also examined, one where SSTs were either allowed to evolve "freely" (no flux adjustments) and one where SSTs were restored to the interannually varying monthly mean values derived from HadISST1.1 (Rayner et al. 2003). Even though HiFLOR was much better at representing SSTs in the flux-adjusted run, both simulations showed biases in TC frequency that closely resemble Fig. 1. The comparable error behavior in the HiFLOR experiments with and without interannual variability suggests that our omission of El Niño-Southern Oscillation (ENSO) is likely not the source of the unique Pacific Ocean biases. In Murakami et al. (2015), the correlations between synoptic-scale parameters in observations and HiFLOR were also high, which suggests that poor representation of the TC environment is not the main source of errors in TC totals. Like most CGCMs, the atmospheric physics and resolution of the model is likely at fault for the large biases, and all conclusions presented here are subject to these uncertainties. In an upcoming study, we examine whether synoptic-scale variables provide an explanation for global and basin-specific biases.

Figure 2 illustrates the spatial distribution of mean annual TC (top) and major hurricane (bottom) density in the 70-yr HiFLOR CTL simulation and compares it to the 1986-2005 annual average of these fields in IBTrACS and ADT-HURSAT. In a large section of the Atlantic, north Indian, South Pacific, and central Pacific regions, HiFLOR matches well with observations. In general, HiFLOR appears to resolve the locations of major hurricanes better than the locations of TCs. As expected from Fig. 1, the main differences between HiFLOR and the observational datasets are visible in the east and west Pacific basin. Both the top and bottom maps show blue and green contours in the east Pacific and red and magenta contours in the west Pacific, respectively highlighting HiFLOR's main area of low and high biases. Figure 2 also highlights HiFLOR's poor performance in the south Indian Ocean, specifically in the $10^{\circ}-25^{\circ} \mathrm{S}$ latitude band between Madagascar and northwest Australia, which was not apparent in Fig. 1. Just east of Madagascar and west of Australia, HiFLOR generates too many TCs and major hurricanes, but in the area between these two landmasses, HiFLOR generates too few TCs and major hurricanes. Additional analysis into spatial biases in this region will be presented in a future study.

Figure 2 also demonstrates that the two observational datasets disagree on the annual number of TCs. A comparison of the top and bottom maps reveals that difference in TC days can be attributed to ADT-HURSAT producing more weak TCs. In the top map of Fig. 2, the additional blue contours without concurrent green contours, and magenta contours without concurrent red contours highlight areas where ADT-HURSAT identifies TCs but IBTrACS does not. In the bottom map of Fig. 2, the colored contours almost overlap, confirming that ADT-HURSAT and IBTrACS agree well on the location and frequency of major hurricanes. The noted known deficiencies in the ADT-HURSAT scheme (in particular, that the absolute accuracy of the intensity estimates are necessarily compromised by the temporal homogenization process) likely cause the slight differences in the plotted fields, and therefore only IBTrACS is included in the following two figures.

Figure 3 shows the percent difference in annual TC (top) and major hurricane days (bottom) in IBTrACS and the HiFLOR CTL simulation and highlights where these differences are significant. Percent difference ${ }^{3}$ is calculated as

\footnotetext{
${ }^{3}$ All percent increases and decreases mentioned in the text are calculated using this equation. Note that this equation bounds percent difference at $-200 \%$ and $+200 \%$.
} 


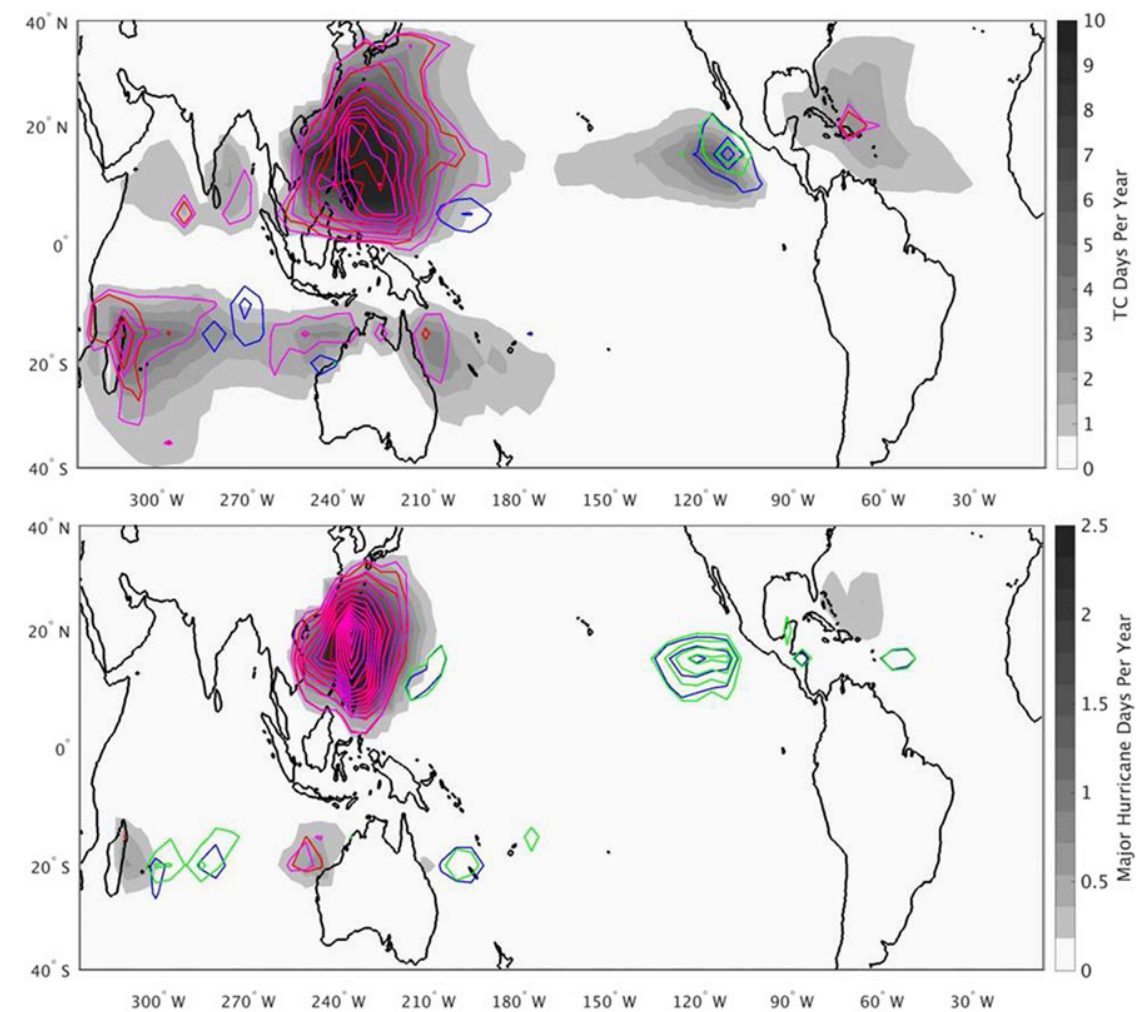

FIG. 2. The annual mean (top) TC and (bottom) major hurricane days in the 70-yr HiFLOR control simulation are shaded in gray. Days are calculated by counting the number of times a TC passes into a $5^{\circ} \times 5^{\circ}$ grid box and dividing by the number of observation increments in a day (i.e., four 6-h increments per day in IBTrACS and HiFLOR, eight 3-h increments per day in ADT-HURSAT). The data are then smoothed with linear interpolation. The highest value on the top and bottom color bars is set $\sim 30 \%$ lower than the maximum recorded value so that the west Pacific maximum does not prevent other geographical locations from displaying contours. Blue and green contours, respectively, demarcate areas where ADT-HURSAT and IBTrACS annually average one ( $1 / 4)$ more TC (major hurricane) day than HiFLOR. Red and magenta contours respectively demarcate areas where ADT-HURSAT and IBTrACS annually average one $(1 / 4)$ less TC (major hurricane) day than HiFLOR. Storms must meet the criteria outlined in section 2 to contribute to the day totals in a grid box.

percent difference in $5^{\circ} \times 5^{\circ}$ grid box

$$
=100 \times \frac{\text { IBTrACS }- \text { HiFLOR CTL }}{(\text { IBTrACS }+ \text { HiFLOR CTL }) / 2} .
$$

Data are only plotted in a grid box if there is at least one TC day per year in HiFLOR and $1 / 4$ of a TC day per year in IBTrACS. Criteria thresholds were independently selected to compensate for the approximately 4 times as many storms in the HiFLOR sample. ${ }^{4}$ A two-sided Mann-Wilcoxon-Whitney test, using Eqs. (5.22a,b) and

\footnotetext{
${ }^{4}$ Even though TC days per year is a normalized quantity, the 70-yr sample in HiFLOR allows for more opportunities for a TC to pass through each grid box than the 20-yr sample in IBTRaCS. Adjusting the plotting threshold based on this inconsistency is somewhat subjective but is mathematically supported.
}

(5.23a,b) from Wilks (2011), determines whether grid boxes are significant. Grid boxes with a $p$ value less than 0.05 are considered statistically significant, and all other grid boxes are demarcated with a white "X." HiFLOR produces significantly more TCs than IBTrACS for large portions of every basin. The only exception is the area surrounding Mexico in the Caribbean Sea, Gulf of Mexico, and east Pacific Ocean. HiFLOR has significantly less TCs than IBTrACS for much of this region.

For the map in Fig. 3 depicting the difference in major hurricanes between HiFLOR and IBTrACS, the east and west Pacific basins are again emphasized as the main areas where the two datasets differ. Only $39 \%$ of plotted grid boxes are statistically significant in the major hurricane map, while $52 \%$ of plotted grid boxes are statistically significant in the TC map. Clearly, HiFLOR is 

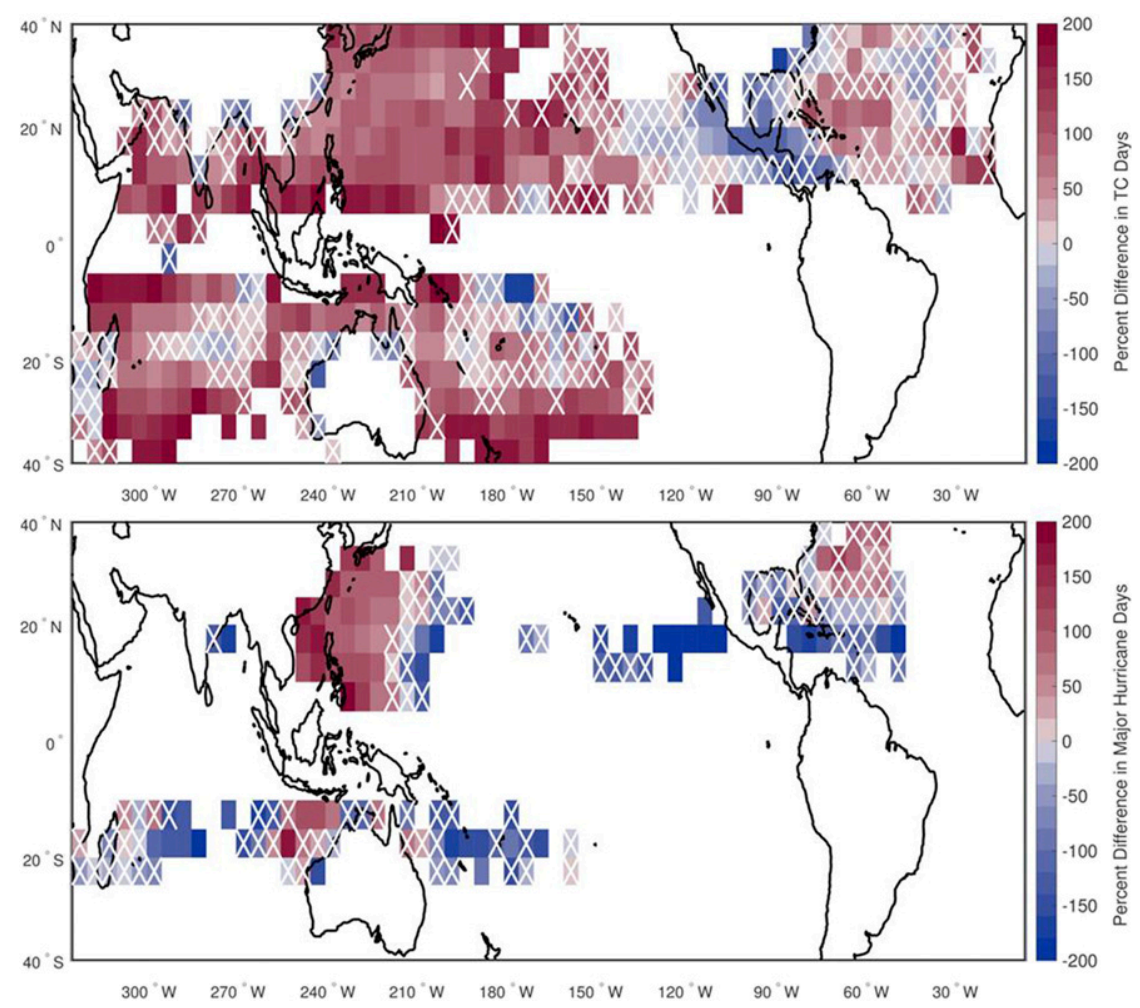

FIG. 3. The percent difference in annual mean (top) TC and (bottom) major hurricane days between the HiFLOR control simulation and IBTrACS. TC (major hurricane) days are calculated by counting the number of times a TC (major hurricane) passes into a $5^{\circ} \times 5^{\circ}$ grid box and dividing by the number of observation increments in a day. Red grid boxes highlight areas where HiFLOR has more days than IBTrACS, and blue grid boxes highlight areas where HiFLOR has fewer days than IBTrACS. Data are only plotted in a grid box if there is at least one TC day in HiFLOR and $1 / 4$ of a TC day in IBTrACS. Grid boxes that achieve a $p$ value of 0.05 using the Mann-Wilcoxon-Whitney test are considered statistically significant. White " $\mathrm{X}$ " marks are located in grid boxes that are not statistically significant.

better at reproducing the geographical distribution of stronger TCs than weaker TCs. The number of major hurricanes captured in the HiFLOR CTL simulation is impressive for a CGCM and enables HiFLOR to resolve the entire breadth of the LMI distribution observed in TCs. Lee et al. (2016) recently showed that RI is a fundamental characteristic of the storms located in the high-intensity tail of the LMI distribution, which broaches the question of whether RI is a common occurrence for strong storms in HiFLOR.

\section{b. Comparing TC intensification statistics}

Figure 4 illustrates how the LMI distribution and the relationship between RI and LMI compare in HiFLOR, ADT-HURSAT, and IBTrACS. Probability density functions (PDFs) are plotted to represent the global LMI distribution of all storms, storms that undergo RI, and storms that do not undergo RI. Following the work of Lee et al. (2016), the intensification rate of $30 \mathrm{kt}$ in
$24 \mathrm{~h}$ is used as the RI threshold. ${ }^{5}$ The same smoothing technique (moving average with window width of $15 \mathrm{kt}$ ) is also applied here.

Figure 4 agrees well with the main results of Lee et al. (2016). PDFs for IBTrACS and ADT-HURSAT are hypothesized to appear less smooth than those in Lee et al. (2016), because we focus on a shorter time period. IBTrACS and ADT-HURSAT LMI distributions have a bimodal structure and the most frequently attained LMI for both datasets is between 55 and $65 \mathrm{kt}$. However, ADT-HURSAT shows an unphysical peak in the number of storms whose LMI is between 55 and $65 \mathrm{kt}$ (Kossin et al. 2013). It is well documented that ADT-HURSAT typically outputs TC intensity just below hurricane strength when the eye of a TC is not visible in the infrared

\footnotetext{
${ }^{5}$ Lee et al. (2016) found this intensification rate was the optimal RI threshold for explaining the bimodality of the LMI distribution.
} 


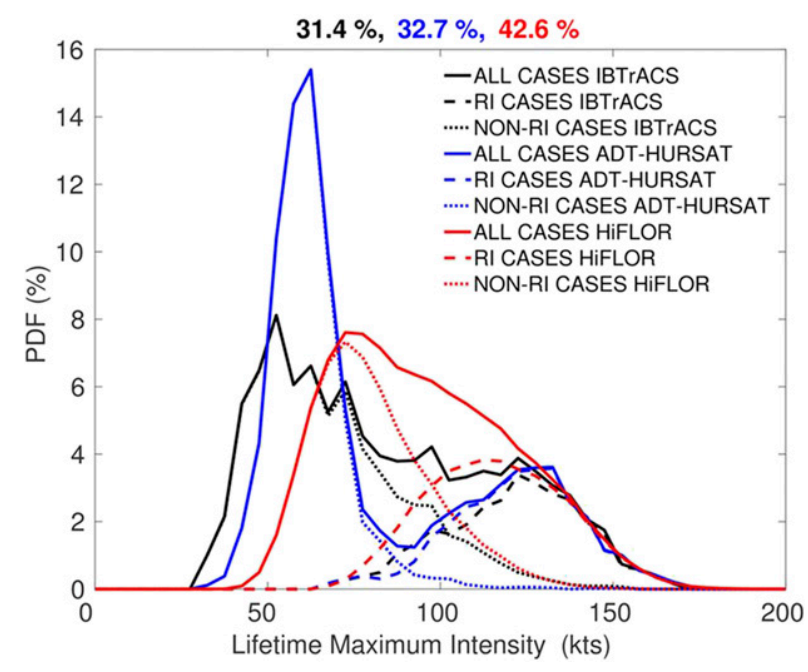

FIG. 4. PDFs of global TC LMI for IBTrACS, ADT-HURSAT, and HiFLOR. ADT-HURSAT (blue) and IBTrACS (black) distributions are calculated using data from 1986 to 2005. HiFLOR (red) distributions are calculated using the 70-yr control run that is nudged to the mean climate during 1986-2005. Raw data are grouped in 5-kt bins and smoothed by a moving average with window width of $15 \mathrm{kts}$. The solid, dashed, and dotted lines show the smoothed PDF for all storms, storms that undergo RI during their lifetime (RI storms), and those that do not (non-RI storms), respectively. The percent of storms that undergo RI is listed in the title with each percent colored according to the dataset.

imagery. Therefore, ADT-HURSAT suggests that an anomalous number of storms maintain their intensities between 55 and $65 \mathrm{kt}$, even though their actual intensities are much higher. After the eye appears, the automated algorithm artificially augments the intensification rate of TCs. IBTrACS intensity estimates are better in this intensity regime because forecasters can use microwave or radar imagery to see the eye of a TC when it is hidden by a cirrus shield (Landsea and Franklin 2013). Thus, ADT-HURSAT LMI features two maxima but its primary maximum is unrealistically large.

The probability distribution in HiFLOR peaks at higher LMI values than both observational datasets. Additionally, the HiFLOR curve does not have the two well-defined maxima found in observational datasets and high-resolution AGCMs (Manganello et al. 2012; Murakami et al. 2012). Murakami et al. (2015) also noted this inconsistency, which suggests it is likely a by-product of the tracking algorithm or deficiencies in the model physics. For example, the warm-core requirements and other components of the tracking procedure in HiFLOR could lower the number of weak TCs, which shifts the LMI distribution and peak to higher values. Alternatively, the atmospheric physics and horizontal resolution of HiFLOR could prevent it from capturing the intensification processes that cause the two distinct peaks.

Another possible explanation for the LMI differences is HiFLOR could be a better representation of the true LMI distribution of TCs than the observational data. Outside the Atlantic basin, most of the world relies on the Dvorak technique for intensity estimation. Dvorak estimates usually avail of satellite imagery with higher resolution than $\mathrm{ADT}$, but there are still large errors when the eye of a TC is shielded by cirrus clouds. The LMI bimodality in observations is potentially an artifact of the uncertainty associated with intensity estimation (Uhlhorn and Nolan 2012). Model output in HiFLOR does not have these issues. Additionally, HiFLOR is sampling many more storms and has larger sample sizes, which could result in a smoother distribution. More analysis on the relationship between RI and LMI in high-resolution numerical simulations of TCs could help clarify if HiFLOR's unique behavior for low-LMI TCs is because of model flaws.

Above $120 \mathrm{kt}$, HiFLOR LMI mirrors the LMI of the two observational datasets. Like ADT-HURSAT and IBTrACS, HiFLOR shows a connection between TCs with high intensification rates and high LMIs. In all three datasets, a majority of the strongest storms undergo RI at some point during their life cycle. However, the unique intensity calculation procedure followed by ADT-HURSAT that causes an exaggerated peak in LMI also results in a disproportionate number of major hurricanes (wind speeds greater than $95 \mathrm{kt}$ ) that undergo RI. Of major hurricanes, $97.9 \%$ experience RI using ADT-HURSAT while only $80.6 \%$ and $81.0 \%$ experience RI in IBTrACS and HiFLOR, respectively. Although HiFLOR captures the relationship between RI and major hurricanes, it differs from ADT-HURSAT and IBTrACS when considering all storms that undergo RI. The percentages at the top of Fig. 4 indicate that $42.6 \%$ of all storms rapidly intensify in HiFLOR but only $31.4 \%$ and $32.7 \%$ of all storms rapidly intensify in IBTrACS and ADTHURSAT.

Figure 5 is similar to Fig. 4 but only contains the solid curves that represent the PDFs of LMI for all storms in the west Pacific (top) and Atlantic basin (bottom). The individual basins have distinct characteristics that agree well with the results displayed in Figs. 1-3. HiFLOR produces TCs in the west Pacific that reach higher LMIs than TCs in both observational datasets, which results in one broad LMI maximum at high wind speeds. ADT-HURSAT and IBTrACS maintain their bimodal distributions, and the relative size of the second, highintensity maximum becomes larger. HiFLOR LMI peaks at almost the same intensity as the second LMI 

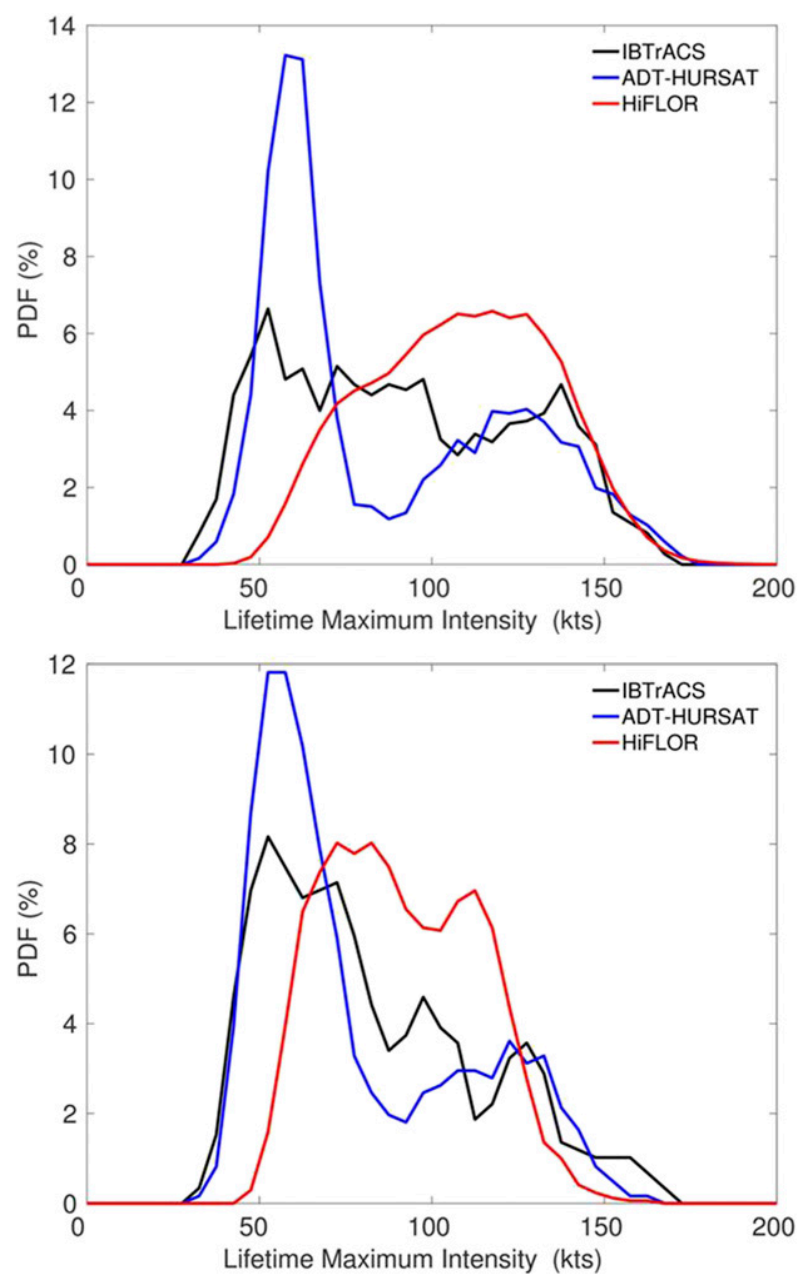

FIG. 5. PDFs of (top) west Pacific and (bottom) Atlantic TC LMI for IBTrACS, ADT-HURSAT, and HiFLOR. The PDFs have the same interpretation as the solid curves in Fig. 4.

peak in the observational datasets, and it matches well with observations beyond $125 \mathrm{kt}$. In the Atlantic basin, the LMI distribution of HiFLOR appears to follow a more bimodal distribution. Unlike the west Pacific, HiFLOR produces too few storms above $140 \mathrm{kt}$ but otherwise matches the observational datasets better.

The intensification characteristics of the different datasets are examined to explain the discrepancies in their RI frequencies and LMI distributions. We only consider the intensity changes that meet the TC longevity and location conditions discussed in section 2 . Figure 6 shows the common logarithm of probability densities calculated from ADT-HURSAT, IBTrACS, and HiFLOR 24-h intensity changes that meet the criteria discussed in section 2. The three different plots show global (Fig. 6, top), west Pacific (Fig. 6, bottom left), and Atlantic (Fig. 6, bottom right) results. The construction of this image closely follows the methodology used to create Fig. 2 in Kowch and Emanuel (2015). To account for the substantially smaller sample sizes of the observational datasets, we randomly subsample the HiFLOR data at the same rate as the observational dataset with the fewest number of cases. This procedure is repeated 1000 times, and the probability densities of the intensity changes for each subsample are then calculated. The mean bin values from all the subsamples are then plotted as a solid red curve to communicate HiFLOR's PDF. Red dashed lines demarcate the 5th and 95th percentiles of the subsamples' intensity changes for each bin. This procedure compensates for the substantially larger number of 24-h intensity changes for HiFLOR compared to IBTrACS and ADT-HURSAT (70 years of data compared to 20 years).

For the global data, the shape of the HiFLOR 24-h intensity change distribution closely mirrors IBTrACS, and the two datasets agree on the probabilities of some bins. For both of these datasets, the bin entries on either side of zero intensity change appear linear, conveying that the probability densities are exponentially distributed. ADT-HURSAT exhibits different behavior, with comparatively lower probabilities for smaller intensity changes and higher probabilities for a majority of the larger intensity changes. One of the most unique features of the ADT-HURSAT distribution is the probabilities of the bins between 30 and $70 \mathrm{kt}$ are almost equal, and the probabilities of bins above this range are significantly higher than those in IBTrACS and HiFLOR. The "shelf" between 30 and $70 \mathrm{kt}$ is likely caused by scene-type changes (from noneye to eye) that lead to large, spurious intensification rates in ADT-HURSAT (Olander and Velden 2007). This explanation corroborates the higher percentage of major hurricanes that undergo RI in ADT-HURSAT, which was discussed in reference to Fig. 4.

Between -40 and $20 \mathrm{kt}$ of intensity change, all three datasets have similar probabilities. These bins account for approximately $83 \%$ of all IBTrACS cases, $86 \%$ of all HiFLOR cases, and $88 \%$ of all ADT-HURSAT cases. However, for a majority of the bins outside of this intensity range, sampling error does not explain the differences in the curves. HiFLOR has significantly less occurrences of the largest positive 24-h intensity changes than both observational datasets. This result is counterintuitive because Fig. 4 revealed that more storms increase their intensity by greater than $30 \mathrm{kt}$ in HiFLOR compared to ADT-HURSAT and IBTrACS. However, for storms that rapidly intensify in HiFLOR, only $6.7 \%$ of all the recorded 24-h intensity changes for those storms are greater than $30 \mathrm{kt}$, while the corresponding percentages in ADT-HURSAT and IBTrACS are $11.1 \%$ 

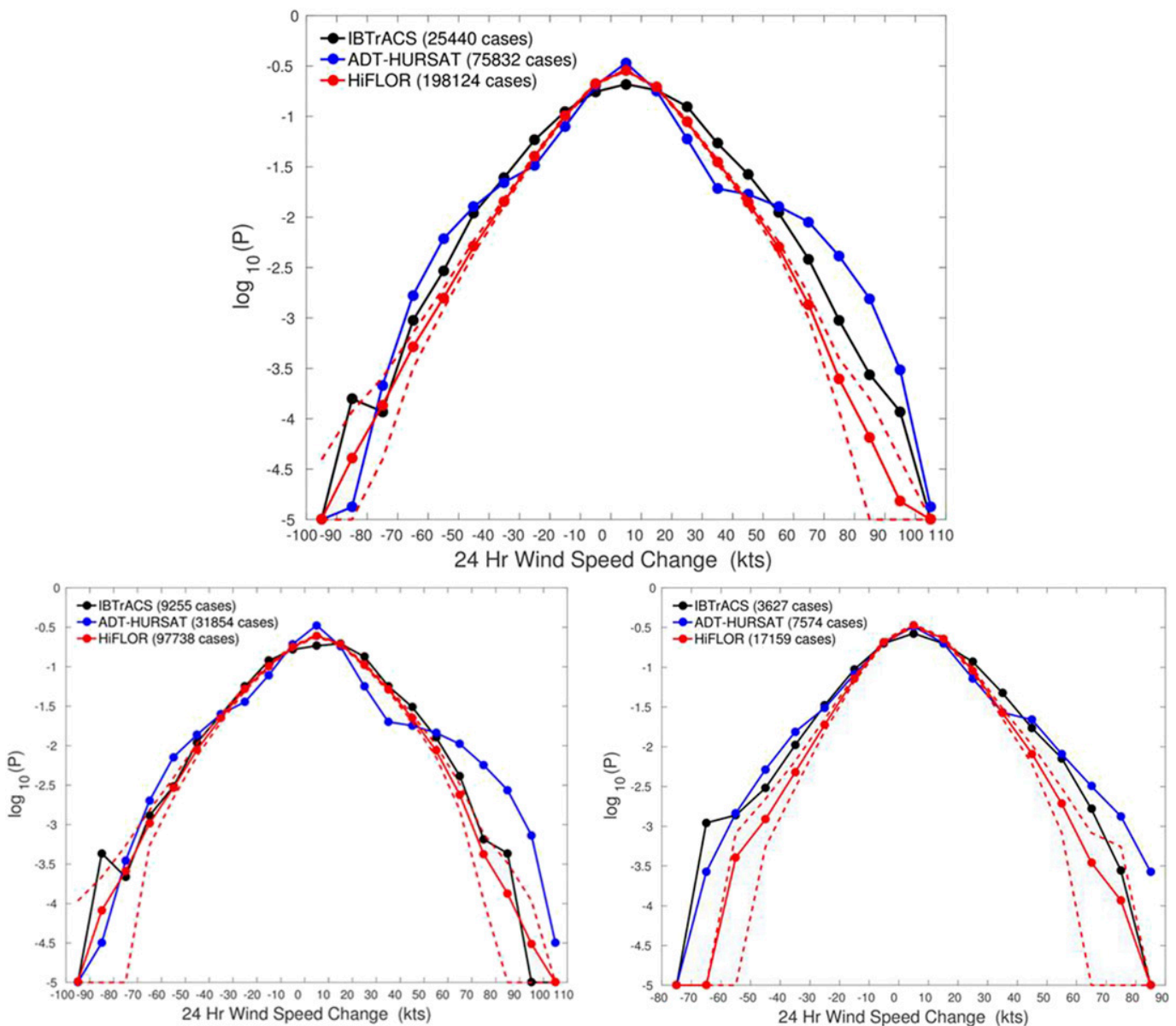

FIG. 6. Common logarithm of the probability densities calculated from IBTrACS (black), ADT-HURSAT (blue), and HiFLOR (red) 24-h intensity changes. Plots generated with (top) global data, (bottom left) west Pacific basin data, and (bottom right) Atlantic basin data. To be included in the sample, the intensity change must occur over open ocean between $40^{\circ} \mathrm{N}$ and $40^{\circ} \mathrm{S}$, and the beginning and ending intensity of the TC must be greater than $34 \mathrm{kt}$. Additional criteria to select storms for evaluation are described in section 2. The number of cases for each dataset is listed in the legend. HiFLOR tracks data are subsampled at the rate of the IBTrACS data for each intensity change bin. The red dashed lines indicate the 5th and 95th percentiles of 1000 subsamples. All distributions are bounded below by $10^{-5}$. The PDFs are truncated horizontally when two of the PDFs have logged a bin with a $y$ value below or equal to $10^{-5}$.

and $14.2 \%$, respectively. Thus, HiFLOR is able to capture the highest 24-h intensity changes observed in nature, but the probability of attaining the extreme intensification rates is too low.

In the west Pacific basin, the ADT-HURSAT probability distribution closely resembles its distribution for the global data. However, ADT-HURSAT still greatly differs from IBTrACS and HiFLOR, which display remarkable agreement for the west Pacific data. HiFLOR and IBTrACS probability distributions are almost identical for the highest intensification and decay rates. Therefore, HiFLOR appears to skillfully resolve intensification processes in the west Pacific, which indicates exaggerated genesis rates might be the cause of HiFLOR overestimating the annual major hurricane count in this basin.
In the Atlantic basin, HiFLOR, ADT-HURSAT, and IBTrACS have similar probability densities between -20 and $20 \mathrm{kt}$. However, at higher intensification rates, HiFLOR has lower probabilities than both observational datasets. The lack of extreme RI events for HiFLOR helps explain the shortage of major hurricanes visible in Fig. 3. However, the annual number of TCs in HiFLOR matches well with the observational datasets in Fig. 1, which suggests that HiFLOR likely generates a realistic number of TCs in the Atlantic basin but is a little conservative in the intensification of TCs.

Figure 6 demonstrates HiFLOR successfully captures the shape of the PDF for 24-h intensity changes but slightly underrepresents the highest intensification events. HiFLOR resembles IBTrACS for individual basins and 


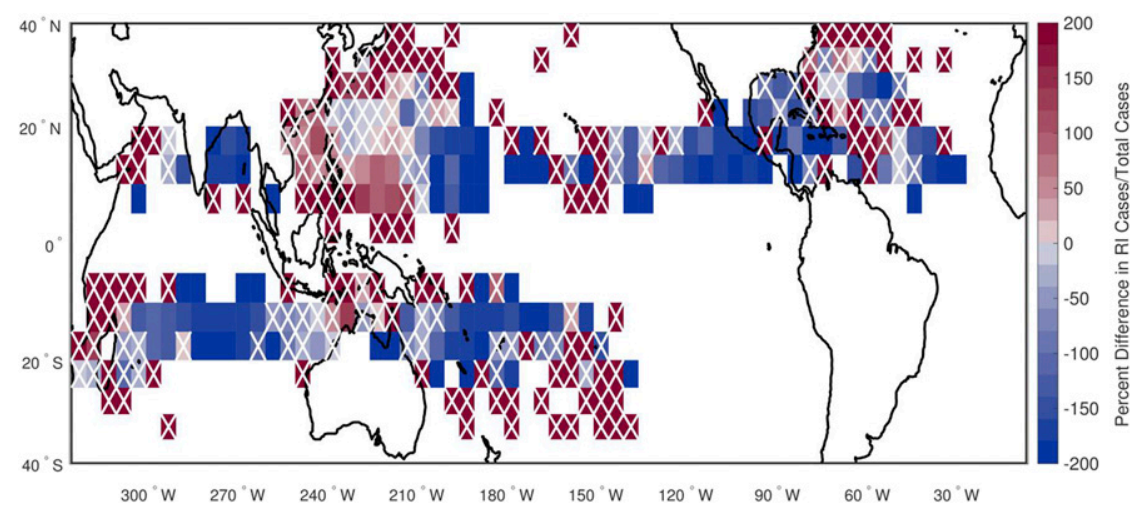

FIG. 7. The percent difference in RI ratio between IBTrACS and HiFLOR is plotted in each $5^{\circ} \times 5^{\circ}$ grid box. Blue (red) squares indicate grid boxes where a larger (smaller) percentage of 24-h intensity changes exceed $30 \mathrm{kt}$ in IBTrACS than in HiFLOR. Grid boxes that achieve a $p$ value of 0.05 using a binomial proportion test are considered statistically significant. White " $\mathrm{X}$ " marks are located in grid boxes that are not statistically significant.

globally but often deviates from ADT-HURSAT. Many of the known deficiencies in ADT-HURSAT, most specifically the documented artificial kurtosis in the LMI distribution, are manifested in the anomalous 24-h intensity change PDFs. Therefore, ADT-HURSAT achieves its original goal of serving as an excellent resource for trend analysis of TCs that achieve hurricane status but is less reliable than IBTrACS for verifying TC intensification. As a result, the following figure focuses only on the geographical distributions of RI in IBTrACS and HiFLOR.

Figure 7 provides a spatial perspective on how well HiFLOR reproduces the largest 24-h intensity changes. Percent difference in RI ratio between IBTrACS and HiFLOR is plotted in each $5^{\circ} \times 5^{\circ}$ grid box, where RI ratio is defined as

$$
\begin{aligned}
& \text { RI ratio in } 5^{\circ} \times 5^{\circ} \text { grid box } \\
& =\frac{\text { number of } 24 \text {-h intensity changes }>30 \mathrm{kt}}{\text { total } 24-\mathrm{h} \text { intensity changes }} .
\end{aligned}
$$

As in Fig. 3, data are only plotted in a grid box if there is at least one TC day per year in HiFLOR and $1 / 4$ of a TC day per year in IBTrACS. Statistical significance is computed using a binomial proportion test with $p$ values below 0.05 considered significant (Suissa and Shuster 1985). Grid boxes that are not statistically significant are demarcated with a white "X." Figure 7 reinforces Fig. 6. The prevalence of blue boxes throughout the bottom map conveys that a smaller percentage of HiFLOR TCs are undergoing RI compared to those in IBTrACS and suggests that HiFLOR underestimates TC intensification in parts of every basin. The western half of the west Pacific basin contains the only sizable area where HiFLOR has a significantly higher RI ratio than
IBTrACS. However, less than a third of all grid boxes that contain TCs show significant differences in RI ratio between IBTrACS and HiFLOR. It is also important to note that the choice of grid box size, significance test, and RI threshold all affect the interpretation of Fig. 7, so its results should be viewed in tandem with Fig. 6.

Further insight into the ability of HiFLOR to resolve TC intensity evolution is possible by evaluating 6-h intensity changes. Figure 8 is similar to Fig. 6 but it compares the common logarithm of probability densities calculated from ADT-HURSAT, IBTrACS, and HiFLOR 6-h intensity changes. Again, plots are created using global (Fig. 8, top), west Pacific (Fig. 8, bottom left), and Atlantic (Fig. 8, bottom right) data. The 3-h measurements for ADT-HURSAT are subsampled every $6 \mathrm{~h}$ to match the other two datasets. The probability density of intensity changes are binned in increments of $2 \mathrm{kth}^{-1}$ instead of listing the absolute changes over 6-h periods. Unlike Fig. 6, the two observational datasets show more similarities with each other than HiFLOR. HiFLOR produces higher-magnitude intensity variations than IBTrACS and ADT-HURSAT, which is the opposite relationship observed for 24-h intensity changes. The probability distributions for the west Pacific are very similar to the global ones. In the Atlantic basin, the HiFLOR curve more closely follows the two observational datasets.

It is likely that the unique shape of the PDF for 6- and 24-h intensity changes in HiFLOR could be attributed to flawed model physics that prevent TCs from maintaining a steady intensity. Considering this reasoning along with the conclusions from Fig. 6, it appears that HiFLOR generates erratic convection that causes too many high-frequency intensity variations, but it does not produce as much sustained and organized convection. 

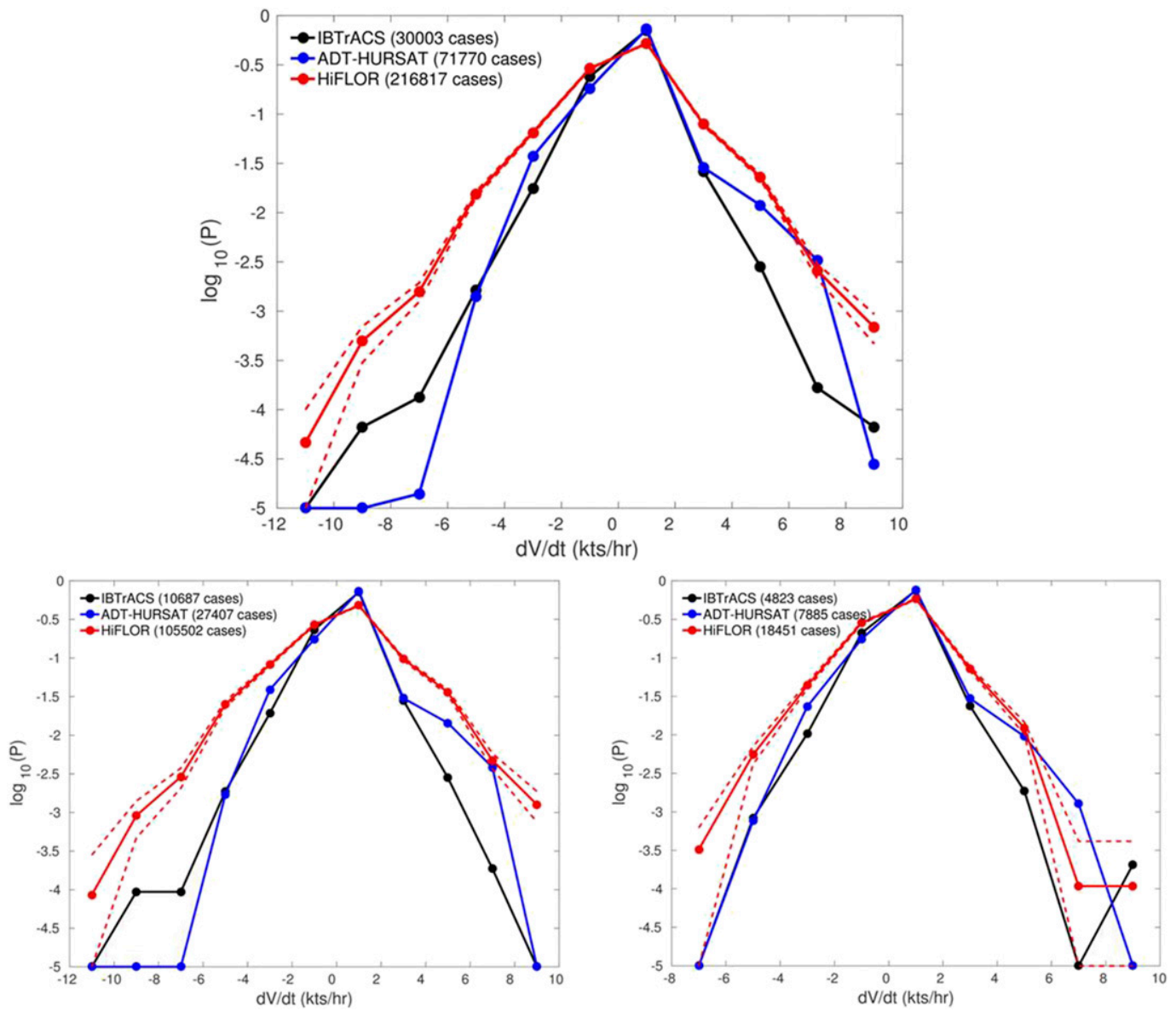

FIG. 8. As in Fig. 6, but for 6-h intensity changes. Each dataset is subsampled every $6 \mathrm{~h}$ and the intensity changes are binned based on their hourly rate.

Alternatively, the significantly fewer 6-h intensity changes of $0 \mathrm{kt}$ in HiFLOR could be because the model framework enables high-frequency intensity variations to be easily detected; in nature, calculations of acceleration rates are much less precise (Uhlhorn and Nolan 2012).

An explanation for these discrepancies can only be tested when additional high-resolution CGCMs are able to produce the entire intensity change spectrum of TCs. Recent work from Davis (2018) suggests that accurate representations of TC intensity and intensification distributions will not be possible until global models further increase their atmospheric resolution. In fact, the Davis (2018) results indicate that HiFLOR is not yet at a resolution that is sufficient to capture major hurricanes. To confirm whether the conclusions of Davis (2018) are valid, additional investigations must include a diverse set of model physics at the same resolution as HiFLOR. These studies would help determine the necessary next steps for better modeling of TC intensification rates in CGCMs. Finally, Scoccimarro et al
(2017) show that better modeling of the air-sea interface would also likely improve future CGCM simulations of TC behavior.

\section{Projected TC response to climate change}

The 70-yr CTL, early, and late HiFLOR simulations are evaluated to determine if, and the extent to which, HiFLOR projects climate change (RCP4.5) to influence the mean intensity and intensification of TCs during the twenty-first century. Murakami et al. $(2015,2016)$ and Zhang et al. (2016) showed that HiFLOR is able to represent many aspects of interannual climate variability and its influence on TCs. However, the connection between low-frequency climate variations [ENSO, the Atlantic multidecadal oscillation (AMO), etc.] and TCs and how their relationship with TCs will evolve with climate change are not considered here. Instead, we use the three HiFLOR simulations to understand the mean TC response during 1986-2005, 2016-35, and 2081-2100. For these three HiFLOR runs, we compare the annual 


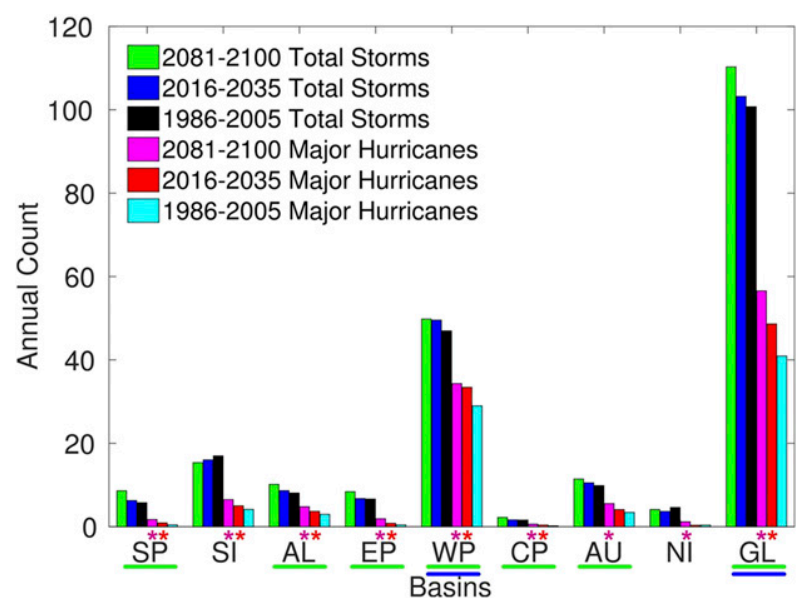

FIG. 9. The annual frequency of TCs and major hurricanes in the 1986-2005, 2016-35, and 2081-2100 HiFLOR simulations. Histograms are plotted for global frequency as well as each basin. The basin identifier on the $x$ axis of the histograms is respectively underlined in green or blue if the annual TC count for the 2081-2100 or 2016-35 simulation is significantly greater than the annual TC count for the 1986-2005 simulation. A magenta or red asterisk on the top-right corner of the basin identifier respectively indicates the 2081-2100 or 2016-35 HiFLOR simulations has significantly more major hurricanes than the HiFLOR control simulation.

frequency of TCs and major hurricanes, the percentage of TCs that become major hurricanes, LMI, the spatial distribution of TCs and major hurricanes, the probability density of 6- and 24-h wind speed changes, and the spatial distribution of RI rates. The storm selection criteria outlined in section 2 as well as the warm-core criteria discussed in Murakami et al. (2015) is applied to the data before analysis.

\section{a. TC intensity projections}

In response to projected twenty-first-century radiative forcing and SST warming, HiFLOR projects the annual global frequency of TCs and major hurricanes to increase. Figure 9 contains histograms for each basin that show the annual mean TC and major hurricane count for the three HiFLOR simulations. As in Fig. 1, unpaired $t$ tests are calculated to determine statistical significance, and a $p$ value of 0.05 is the threshold for significance. Table 1 shows the percent difference between the climate change simulations and the CTL simulation for different TC intensity and intensification metrics. Excluding the north and south Indian Ocean, the globaland basin-average TC count increases as the twenty-first century progresses. Though the projected changes are larger at the end of the century, the period 2016-35 shows a significant global mean increase of $2.5 \mathrm{TCs}$ per year $(+2.4 \%)$ compared to the period 1986-2005. For the last 20 years of the twenty-first century, HiFLOR projects 9.5 more TCs per year $(+9.1 \%)$ than the annual TC count during the period 1986-2005. This result is consistent with the HiFLOR response to idealized carbon dioxide doubling (G. Vecchi et al. 2018, manuscript submitted to Climate Dyn.), suggesting that increasing greenhouse gases are the main driver of the additional TCs.

Although HiFLOR indicates that the future climate will likely have more TCs, the more robust signal involves the trend in major hurricanes. Both globally and in individual basins, there are significantly more major hurricanes in the HiFLOR late simulation than the HiFLOR CTL simulation. HiFLOR even suggests that there will be a significant increase in major hurricanes by the early part of the twenty-first century, and only the north Indian and Australian basin do not show a significant increase between the 1986-2005 run and the 2016-35 run. Globally, the early and late climate change experiments have $11.1 \%$ and $20.3 \%$ more major hurricanes than the CTL experiment, respectively. Individual basins log substantially higher percent increases. For example, HiFLOR projects the east Pacific and South Pacific basins respectively to have $23.4 \%$ and $33.1 \%$ more TCs and $69.6 \%$ and $60.6 \%$ more major hurricanes at the end of the twenty-first century compared to the end of the twentieth century.

The upward trend in major hurricanes observed in HiFLOR is in agreement with a majority of published research on climate change projections and TCs (Knutson et al. 2010; Walsh et al. 2016; Camargo and Wing 2016; Bacmeister et al. 2018). The model's projected major hurricane response is comparable to its response to idealized carbon dioxide doubling (G. Vecchi et al. 2018, manuscript submitted to Climate Dyn.), suggesting a consistent relationship with increasing greenhouse gases and a property of this model. Additionally, in the context of other GCM and dynamical downscaling studies, HiFLOR's prediction of more TCs in response to climate change is very unique. According to the recent review articles by Walsh et al. (2015) and Camargo and Wing (2016), AGCMs, CGCMs, and dynamical downscaling consistently forecast a reduction in global TCs due to changes in radiative forcing and SST warming. However, there is no accepted theory that explains why changes to the climate system should favor increased intensification but not more TC genesis.

The emergence of HiFLOR as a contrarian model is not completely surprising, because it is the first CGCM with atmospheric resolution as fine as $0.25^{\circ} \times 0.25^{\circ}$ that has produced multidecadal climate change projections of TCs. Additionally, recent studies (Emanuel et al. 2008, 2013; Korty et al. 2017; Zhang et al. 2017) using a statistical-downscaling scheme have predicted an increase in TC global frequency in response to SST 
TABLE 1 . The percent difference between the number of total storms, major hurricanes, category 4 hurricanes, category 5 hurricanes, and number of storms that undergo RI (at least one $>30$-kt intensity change) in the HiFLOR climate change simulations compared to the HiFLOR control simulation. For each storm type and basin combination, the first entry in the table cell is the percent difference between the 2016-35 and 1986-2005 HiFLOR simulations and the second entry is the percent difference between the 2081-2100 and 1986-2005 HiFLOR simulations. Positive values indicate percent increases in the climate change simulation. Entries marked with a dash (-) signify basin/storm type pairings that have no storms in the CTL simulation and the climate change simulation.

\begin{tabular}{lccccc}
\hline \hline Basin/storm type & Total storms & Major hurricanes & Category 4 & Category 5 & RI storms \\
\hline South Pacific (SP) & $8.8,39.8$ & $40.8,65.7$ & $26.1,133.3$ &,- 200.0 & $38.6,94.3$ \\
South Indian (SI) & $-5.8,-10.1$ & $12.1,27.5$ & $26.6,62.9$ & $200.0,200.0$ & $38.3,60.8$ \\
Atlantic (AL) & $6.8,22.7$ & $13.9,29.2$ & $27.5,72.9$ & $46.2,135.5$ & $40.7,70.0$ \\
East Pacific (EP) & $1.7,23.4$ & $36.6,69.6$ & $93.3,162.8$ &,- 200.0 & $73.5,131.7$ \\
West Pacific (WP) & $5.4,5.8$ & $9.3,10.9$ & $10.6,1.0$ & $48.50,80.1$ & $15.4,22.3$ \\
Central Pacific (CP) & $2.7,33.1$ & $41.8,60.6$ & $66.7,111.1$ &,--118.5 & $43.2,85.1$ \\
Australian (AU) & $6.4,14.8$ & $11.8,29.4$ & $39.3,79.2$ & $48.3,11.5,46.2$ \\
North Indian (NI) & $-23.1,-11.5$ & $-5.4,58.9$ & $33.3,128.6$ & $-200.0,133.3$ & $27.8,100.8$ \\
Global (GL) & $2.4,9.1$ & $11.1,20.3$ & $16.2,27.7$ & $50.0,85.3$ & $21.7,39.8$ \\
\hline
\end{tabular}

warming and $\mathrm{CO}_{2}$ increases. HiFLOR's ability to resolve the upper tail of the LMI distribution as well as a majority of the strongest intensity changes observed in nature suggests that HiFLOR projections represent a plausible scenario for TC evolution over the twenty-first century. Regardless, a future manuscript will address whether TC-relevant large-scale conditions can explain HiFLOR's behavior in the different simulations and inconsistencies with other studies.

Major hurricane frequency experiences a larger upward trend than overall TC frequency, which indicates that an increase in TC genesis events is likely insufficient to explain the additional strong TCs at the end of the twenty-first century. In Fig. 10, global and basin histograms of the number of major hurricanes divided by the total number of TCs corroborate this hypothesis. This normalized quantity is plotted for each HiFLOR simulation and succinctly highlights that HiFLOR is projecting a larger percentage of storms to reach major hurricane status because of climate change. Every basin shows an increase in the percentage of major hurricanes, but the basins that initially have a smaller percentage appear to be most affected by climate change in HiFLOR.

Figures 9 and 10 also communicate that there will be more TCs in a warmer climate and the strongest storms will occur more frequently than what was observed at the end of the twentieth century. HiFLOR climate change experiments signal that TCs will more routinely reach wind speeds that are well above the category 5 threshold (137 kt), hinting that the Saffir-Simpson scale might need to be extended to include higher categories in the early twenty-first century. Figure 11 shows the PDF of global TC LMI in each of the three HiFLOR experiments. The PDFs were constructed in the same manner as the solid curves in Fig. 4. The entire LMI distribution shifts to higher-intensity values in the HiFLOR climate change simulations, with projected changes stronger at the end of the twenty-first century. The increased probability of higher-intensity TCs becomes more tangible when focusing on the number of TCs that exceed $165 \mathrm{kt}$ in each simulation, which is the fastest wind speed ever recorded during a TC landfall (Typhoon Haiyan; Takagi and Esteban 2016). In the 70-yr HiFLOR CTL experiment, nine TCs achieve a wind speed of greater than $165 \mathrm{kt}$. The number of TCs that exceed this threshold grows to 32 for the 2016-35 simulation and 72 for the 2081-2100 simulation. HiFLOR projects a large increase in the number of TCs with winds exceeding $165 \mathrm{kt}$, but in

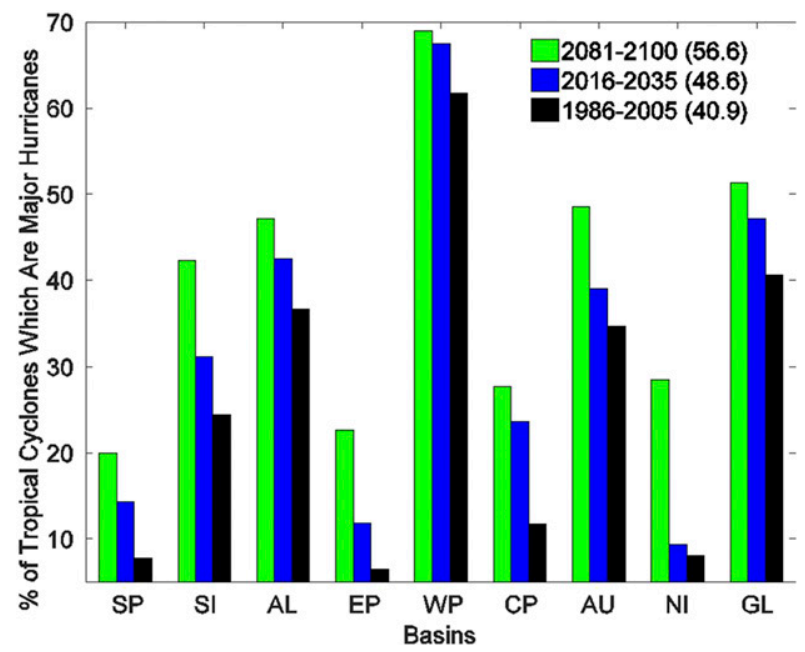

FIG. 10. The percent of TCs that reach major hurricane status for HiFLOR 1986-2005, 2016-35, and 2081-2100 simulations. Histograms are plotted for global as well as basin-specific percentages. The numbers at the end of each legend entry correspond to the global annual number of major hurricanes in each simulation. 


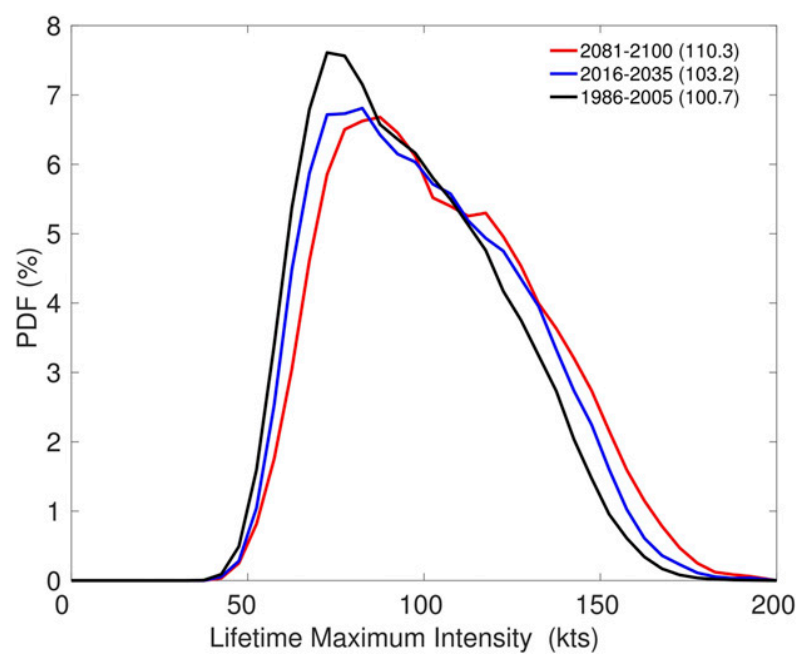

FIG. 11. PDFs of global TC LMI for HiFLOR 1986-2005, 201635, and 2081-2100 simulations. All three distributions are calculated using 70 years of data for TCs meeting the criteria outlined in section 2. Raw data are grouped in 5-kt bins and smoothed by a moving average with window width of $15 \mathrm{kts}$. The mean annual TC count for each simulation is listed in the legend.

order to further assess how these changes will contribute to societal risks, we must explore their spatial structure.

Figure 12 shows the spatial distribution of the annual mean TC (top) and major hurricane (bottom) days in the 70-yr HiFLOR CTL simulation as well as the differences between HiFLOR simulations. TC and major hurricane days for the HiFLOR CTL simulation are shaded in gray, which uses the same data as Fig. 2. In general, both maps in Fig. 12 confirm the results presented in Figs. 9 and 10. However, these maps provide more specific information about where the highest anomalies are located within each basin. The largest increases in annual TC days are often collocated where the highest annual totals of TCs occur in the CTL simulation. For example, the main development region in the west $\mathrm{Pa}$ cific shows the largest increases in major hurricane and TC days, which leads to additional landfalling TCs in Taiwan and the Philippines. Two other areas that are forecasted to have an elevated threat of TC landfall are Hawaii and the southeastern United States, which is also a robust result in other studies (Murakami and Wang 2010; Colbert et al. 2013; Murakami et al. 2013; Knutson et al. 2015).

Figure 13 shows the percent difference in TC (top) and major hurricane (bottom) density between HiFLOR simulations. In Fig. 12, the departures from the HiFLOR CTL simulation displayed similar patterns in the early and late HiFLOR simulations. Thus, Fig. 13 only incorporates the 2081-2100 and 1986-2005 simulations because their differences are more expansive and significant.
The top image of Fig. 13 reveals that many of the spatial differences noted in the discussion of the top image of Fig. 12 are significant. Unsurprisingly, the large number of red contours in the west Pacific did not translate into significant grid squares because the percent increase in these locations is lower. The western Atlantic and central Pacific highlights the large significant increases in TC days observed in Fig. 12, which results in more landfalling TCs in both regions. All of the significant decreases in TC days are clustered between $30^{\circ} \mathrm{S}$ and $30^{\circ} \mathrm{N}$ in the south Indian, north Indian, western Australian, and western Pacific basins. Further investigation is necessary to understand why this region is exhibiting the opposite relationship with climate change compared to the rest of the globe.

The bottom map of Fig. 13 indicates that by the end of the twenty-first century there will be widespread significant increases in major hurricane density. In fact, there are no grid boxes that show a future significant decrease. Many of the grid boxes in the Eastern Hemisphere that recorded significant decreases in TC days experience significantly more major hurricane days in the HiFLOR late simulation. Landmasses in the west Pacific, Australian, and Atlantic basins are highlighted as more prone to major hurricane impacts in the future, which has important socioeconomic implications for these regions. The spatial distributions and histograms plotted in Figs. 9-13 provide a consistent message. The 2081-2100 and 2016-35 HiFLOR simulations exhibit an increase in TCs and especially major hurricanes compared to the 1986-2005 simulation. The spatial configuration of these additional TCs and major hurricanes are similar in the two climate change simulations and hint at an increased TC landfall risk as the twenty-first century advances.

\section{b. TC intensification projections}

The additional major hurricanes projected in both HiFLOR climate change simulations coupled with the relationship between RI and LMI introduced by Lee et al. (2016) suggests the future increase in strong storms could be linked to more frequent extreme TC intensification. Figure 14 shows the common logarithm of probability densities calculated using 24-h global intensity changes from the HiFLOR CTL, early, and late simulations. This image is created following the same methodology as Fig. 6 and only includes data points that are intensity changes from TCs whose circulation centers occur over the ocean, initial and final intensity are greater than $34 \mathrm{kt}$, and circulation center stays at a latitude between $40^{\circ} \mathrm{N}$ and $40^{\circ} \mathrm{S}$. We randomly resample the HiFLOR CTL data 1000 times, and the probability densities of the intensity changes for each subsample are 

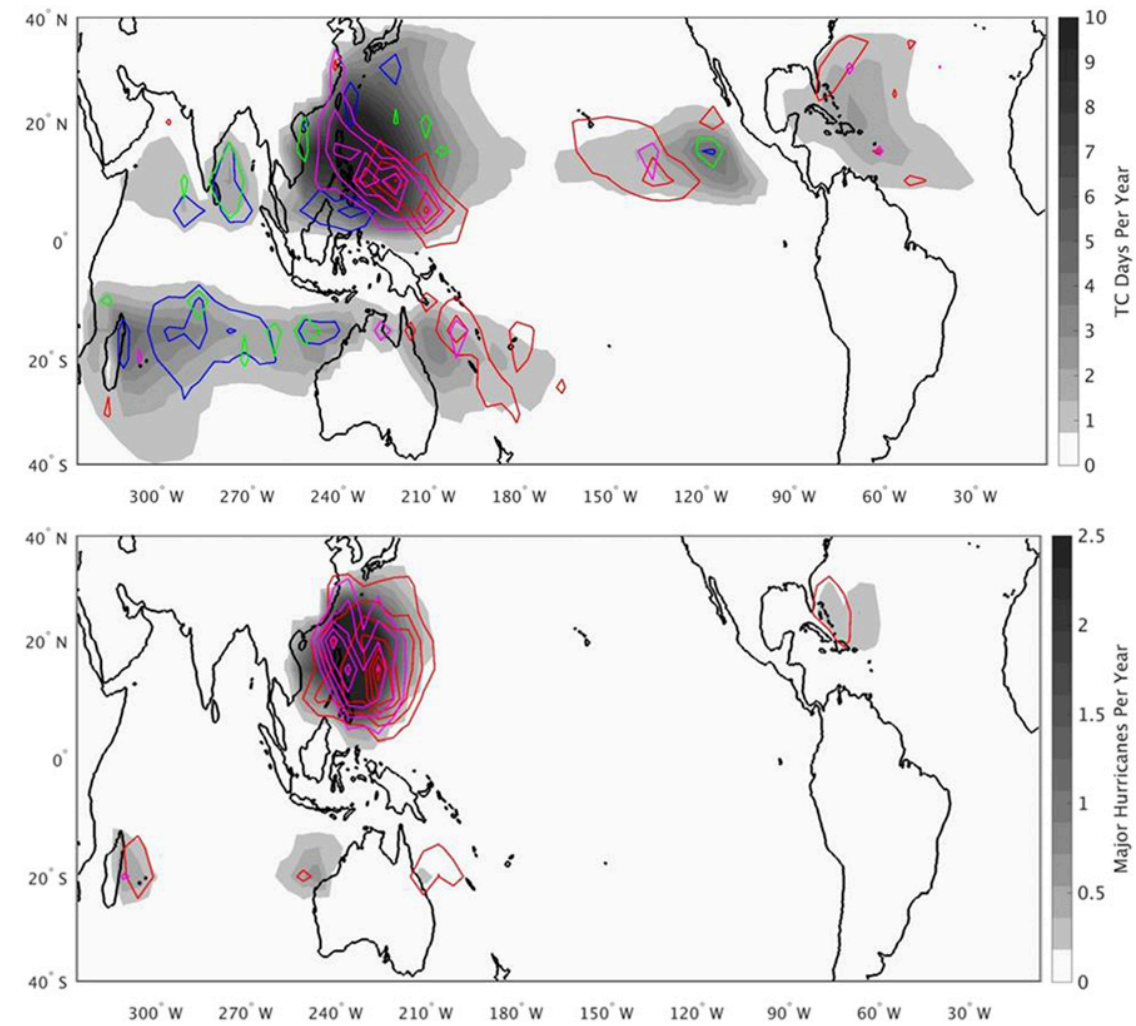

FIG. 12. The annual mean (top) TC and (bottom) major hurricane days in the 70-yr HiFLOR control simulation are shaded in gray. These fields are exactly the same as in Fig. 2 and are calculated the same way. Blue and green contours respectively demarcate areas where the 2016-35 run and 2081-2100 run annually average $1 / 2(1 / 4)$ less TC (major hurricane) days than the 1986-2005 run. Red and magenta contours respectively demarcate areas where the 2016-35 run and 2081-2100 run annually average $1 / 2(1 / 4)$ more TC (major hurricane) days than the 1986-2005 run.

then calculated. Black dashed lines in Fig. 14 demarcate the 5th and 95th percentiles of these intensity changes for each bin.

The 2081-2100 and 2016-35 simulations have significantly more $24-\mathrm{h}$ intensity changes above $40 \mathrm{kt}$ than the 1986-2005 simulation. The 1986-2005 simulation has zero 24 -h intensification events of $100 \mathrm{kt}$ or more, but the early and late simulations respectively have 5 and 11 of these events. The corresponding plot for 6-h intensity changes is not shown here because like Fig. 14, the HiFLOR climate change runs exhibit a similar increase in the probability of high intensification rates. Together, these results suggest that the TC acceleration will rise in response to climate change, which provides TCs with more opportunities to reach higher wind speeds.

Figure 15 shows the spatial structure of 24-h intensification changes in the HiFLOR climate change simulations and is assembled using the same methodology as Fig. 7. The top image of Fig. 15 shows the percent difference in RI ratio between the HiFLOR 1986-2005 and 2016-35 simulations, and the bottom image shows the percent difference in RI ratio between HiFLOR 19862005 and 2081-2100 simulations. Only grid boxes with at least one TC day in the HiFLOR CTL and HiFLOR climate change simulations are included in the analysis. Without this restriction, Fig. 15 would illustrate that several regions without RI in the HiFLOR CTL simulation are projected to experience RI in the future. The top map shows that 30 years of SST warming and radiative forcing significantly increases the likelihood of RI in a majority of grid boxes. This result is particularly notable because HiFLOR indicates there are several clusters of grid boxes close to land that will already have significantly higher probabilities of RI by 2016-35.

A number of other studies have presented model results that project more major hurricanes in a warmer climate, but they have not demonstrated how TCs reach these higher wind speeds. In this study, HiFLOR signals that climate change could allow TCs to rapidly intensify over a larger portion of the world's oceans and increase TC intensification rates dramatically. This result is consistent with the fact that geometry of the ocean basins that have favorable conditions for TC intensification 

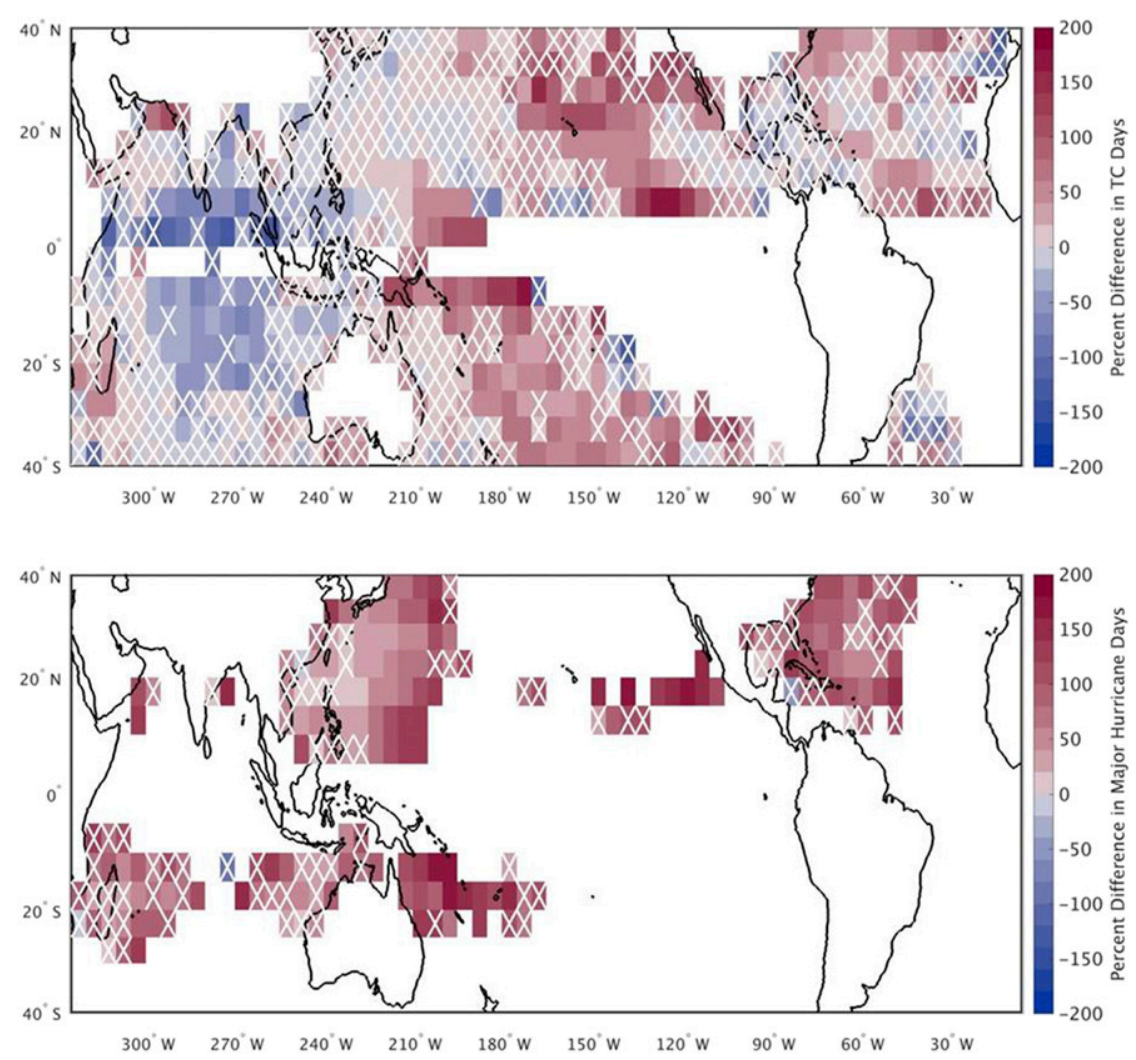

FIG. 13. The percent difference in annual mean (top) TC and (bottom) major hurricane days between the HiFLOR 1986-2005 simulation and HiFLOR 2081-2100 simulation. TC and major hurricane days are calculated in the same manner as Fig. 3. Red grid boxes highlight areas where the HiFLOR 1986-2005 simulation has fewer days than the HiFLOR 2081-2100 simulation, and blue grid boxes highlight areas with the opposite relationship. Data are only plotted in a grid box if there is at least one TC day in each simulation. Grid boxes that achieve a $p$ value of 0.05 using the Mann-Wilcoxon-Whitney test are considered statistically significant. White " $\mathrm{X}$ " marks are located in grid boxes that are not statistically significant.

provides a limited temporal and spatial window for TCs to attain their maximum intensity. If there are going to be stronger and more frequent intense TCs because of climate change, the favorable areas for TC development must expand or TC acceleration rates must accordingly rise; both of these trends are observed in HiFLOR.

The bottom map of Fig. 15 shows the percent difference in RI ratio between the ends of the twentieth and twenty-first centuries, and as expected, there are substantially more significant grid boxes. Augmented intensification rates have a spatially uniform response to increased radiative forcing and SST warming in the HiFLOR model. We also computed the fields plotted in Fig. 15 with higher and lower thresholds for RI. The variations in RI definition yield similar results but, as observed in Fig. 14, the highest intensification rates are the most affected by climate change in HiFLOR. Additional model projections with more high-resolution CGCMs should be developed and compared to HiFLOR in order to determine if there is a consensus on escalating TC hazards over the twenty-first century.

\section{Conclusions and future work}

Three 70-yr, nudged-SST experiments in the highresolution CGCM HiFLOR were introduced as a framework for understanding how climate change could influence TC intensity and intensification. Similar to a "forced SST" AGCM framework, the nudged-SST setup aims to prevent significant biases arising in the model (Vecchi et al. 2014), while still allowing moderate coupling (within a time scale of $\tau$ ) between the ocean and atmosphere. Although this technique isolates the mean climate change signal, the potential drawback is any climate change-induced impacts to internannual variability are unresolved.

The HiFLOR CTL experiment, representative of the period 1986-2005, was first compared to two observational 


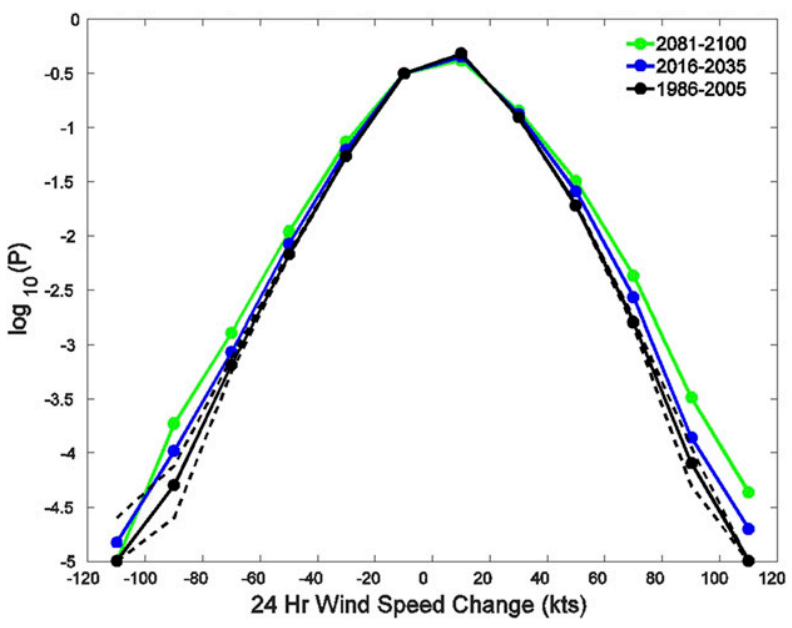

FIG. 14. Common logarithm of probability densities calculated from HiFLOR 24-h global intensity changes for the years 19862005 (black), 2016-35 (blue), and 2081-2100 (green). To be included in the sample, a 24-h intensity change must meet the storm selection criteria described in section 2. The black dashed lines indicate the 5th and 95th percentiles of 1000 subsamples of the HiFLOR 1986-2005 data. All distributions are bounded below by $10^{-5}$. The PDFs are truncated horizontally when one of the PDFs contains a bin with a $y$ value below or equal to $10^{-5}$.

datasets. For this $20-\mathrm{yr}$ period, IBTrACS and ADTHURSAT were deemed as the two most capable observational datasets for evaluating the mean TC intensity and intensification behavior in HiFLOR. The strengths and weaknesses of both datasets were briefly summarized, and we demonstrated that IBTrACS displayed the more credible TC behavior for this particular study. The simulated distribution of TC intensity by HiFLOR is comparable to observations, but some important differences were highlighted. HiFLOR generates significantly more TCs and major hurricanes in the west Pacific and Australian basins. In the east Pacific, HiFLOR has significantly less TCs and major hurricanes than what is observed in nature. The sizeable high biases in the most active basins overwhelm the global totals, and consequently, HiFLOR produces about $15 \%-25 \%$ more global TCs than observations.

HiFLOR distinguishes itself from other CGCMs with its ability to simulate extremely intense TCs and intensification rates. Using a separate set of experiments, Murakami et al. (2016) first showed that HiFLOR could reproduce major hurricanes with similar or more skill than other current high-resolution AGCMs (Murakami et al. 2012; Manganello et al. 2012), dynamical downscaling studies (Knutson et al. 2008, 2013, 2015), and statistical-dynamical downscaling schemes (Emanuel et al. 2008; Emanuel 2006; Emanuel et al. 2006). After comparing the HiFLOR control experiment in this study, which has SSTs nudged to observed values, with the free-running coupled model in Murakami et al. (2015), it is clear that HiFLOR is even better at resolving the strongest TCs after partially correcting for SST biases.

The connection between major hurricane frequency and high intensification rates in observations surfaced in the HiFLOR CTL experiment. As a result, the PDF of intensity changes in the HiFLOR CTL experiment was found to be similar to the observed PDFs. However, the highest 24-h intensification rates found in nature were underrepresented in HiFLOR, and the highest 6-h intensification rates had inflated probabilities in HiFLOR. The different sign of the discrepancies based on the selected time frame could be explained by uncertainty in real-time TC intensity estimates or shortcomings in the HiFLOR model formulation. With the development of more high-resolution CGCMs, further analysis into the source of these inconsistencies will be possible.

As one of the only CGCMs that can resolve the strongest TCs and intensity changes observed in nature, HiFLOR offers a meaningful perspective on how climate change might affect TC behavior. Two climate change experiments, representing the projected mean climate during 2016-35 and 2081-2100 (RCP4.5 scenario), were compared to the HiFLOR CTL experiment. These experiments provide the first multidecadal climate change projections from a CGCM that can resolve major hurricanes. The climate change response in HiFLOR differs from other published AGCM and downscaling studies because it projects a minor, yet significant, increase in TCs in a warmer climate. At the same time, our analysis showed that a warming climate will provide more favorable conditions for the most intense hurricanes, which agrees well with the consensus in the field (Walsh et al. 2016).

The most notable climate change signal in HiFLOR is the increase in the probability of higher intensification rates. Even though only 30 years pass between the CTL and early experiment, HiFLOR forecasts large portions of every basin to experience a significant increase in the percentage of TCs that undergo RI. The changes increase in area and magnitude by the end of the twentyfirst century, with a majority of the TC-prone coastal regions around the world showing a significantly higher RI probability. RI events are responsible for intensity forecasts with the highest errors and thus, additional TCs that rapidly intensify before land would create more unprepared and vulnerable communities (Emanuel 2017; Kossin 2017).

TC projections produced by HiFLOR, like all climate models, have significant uncertainties. However, the realistic intensification and intensity distributions produced by the HiFLOR CTL experiment, coupled with 

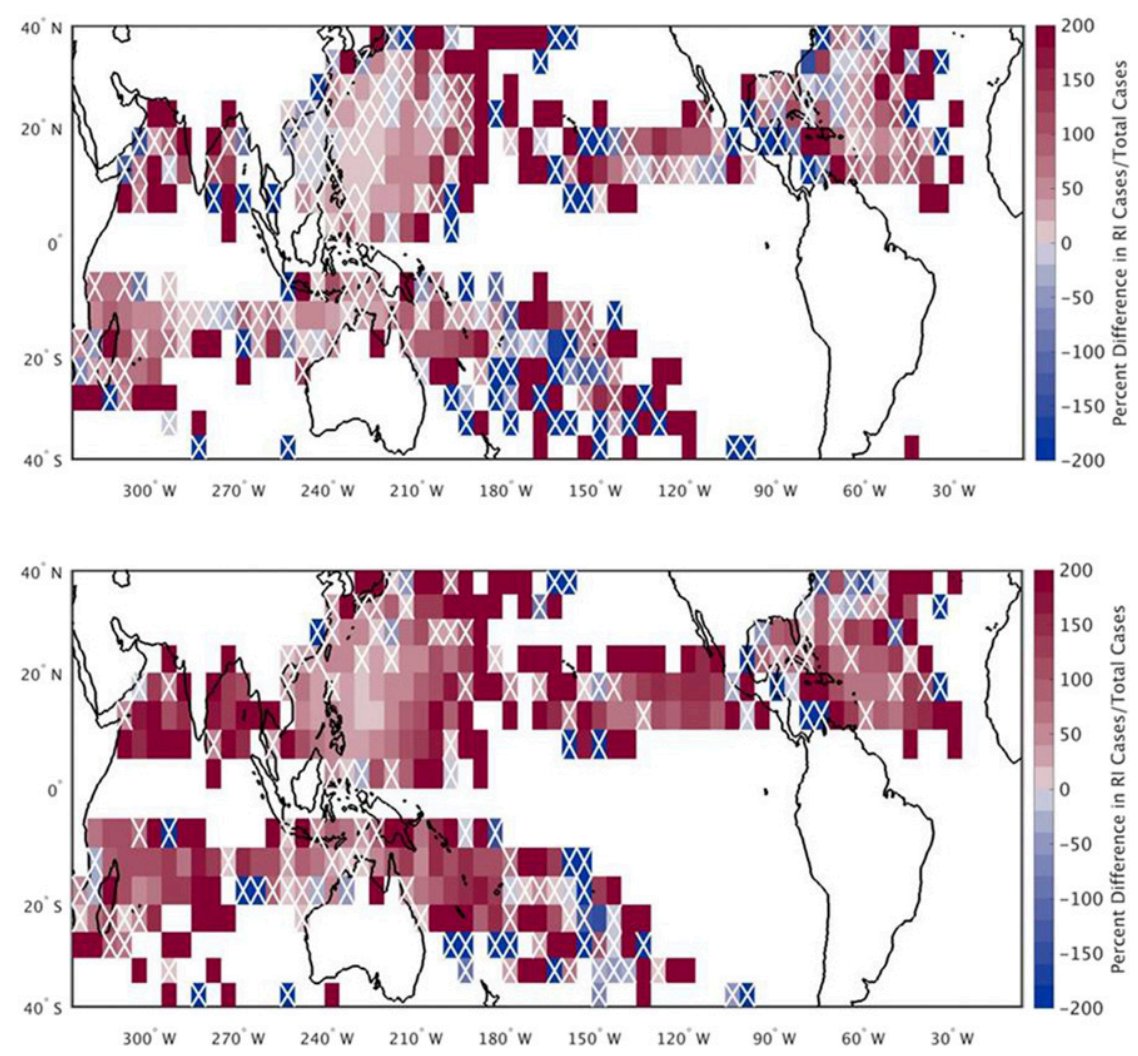

FIG. 15. The percent difference in RI ratio between HiFLOR simulations for the years (top) 1986-2005 and 2016-35 and (bottom) 1986-2005 and 2081-2100 is plotted in each $5^{\circ} \times 5^{\circ}$ grid box. Red (blue) squares indicate grid boxes where a larger (smaller) percentage of 24-h intensity changes exceed $30 \mathrm{kt}$ in the climate change simulations than in the control simulation. Grid boxes that achieve a $p$ value of 0.05 using a binomial proportion test are considered statistically significant. White " $\mathrm{X}$ " marks are located in grid boxes that are not statistically significant.

its bullish forecast for the class of TCs that poses the largest threat to society, demands the attention of the scientific community. The metrics calculated here for HiFLOR can serve as a benchmark when testing the fidelity of other high-resolution CGCMs. As CGCMs advance with more complex physical schemes and better resolution, it will be important to diagnose if intensification and intensity behavior follows or deviates from that in HiFLOR. If HiFLOR's projections prove to be reliable, then they would necessitate significant planning and policy reevaluations for society as the twenty-first century progresses.

HiFLOR's ability to capture the strongest TCs and intensification rates and the model's TC response to projected changes in radiative forcing and SSTs have inspired two complementary manuscripts. To explore a physical explanation for the climate change response of TCs in HiFLOR, an upcoming study will evaluate the sensitivity of TCs in these HiFLOR experiments to synoptic-scale variables. Murakami et al. (2015) already showed that HiFLOR is very skillful at predicting and reproducing these large-scale parameters. A preliminary investigation with our three experiments shows that HiFLOR displays a realistic relationship between synoptic variables and TC activity. If further analysis confirms this behavior, we can investigate whether synoptic variables serve as possible pathways for a warming climate to affect TC intensification. A second study (Bhatia et al. 2018, manuscript submitted to Nat. Commun.) will address whether the upward intensification rate trends in HiFLOR projections are detectable in the recent trends of observational datasets. IBTrACS and ADT-HURSAT are used to calculate TC intensity changes, normalized by the total number of cases, over the last 30 years. Normalized global and basin TC acceleration rates are found to significantly increase, which is consistent with the well-documented growth of major hurricanes in recent decades (Holland and Bruyère 2014). The trends in the observational datasets will be compared to multicentury simulations produced by HiFLOR. 
Acknowledgments. The authors thank Dr. Andrew Hazelton and Dr. Thomas Knutson for their suggestions and comments during the internal review process. Kieran Bhatia and Gabriel Vecchi were supported by National Science Foundation under Grant AGS1262099 and in part by the Carbon Mitigation Initiative at Princeton University BP International 02085(7).

\section{REFERENCES}

Bacmeister, J. T., M. F. Wehner, R. B. Neale, A. Gettelman, C. Hannay, P. H. Lauritzen, J. M. Caron, and J. E. Truesdale, 2014: Exploratory high-resolution climate simulations using the Community Atmosphere Model (CAM). J. Climate, 27, 3073-3099, https://doi.org/10.1175/JCLI-D-13-00387.1.

— , K. A. Reed, C. Hannay, P. Lawrence, S. Bates, J. E. Truesdale, N. Rosenbloom, and M. Levy, 2018: Projected changes in tropical cyclone activity under future warming scenarios using a high-resolution climate model. Climatic Change, 146, 547-560, https://doi.org/10.1007/s10584-016-1750-x.

Bender, M. A., and I. Ginis, 2000: Real-case simulations of hurricane-ocean interaction using a high-resolution coupled model: Effects on hurricane intensity. Mon. Wea. Rev., 128, 917-946, https://doi.org/10.1175/1520-0493(2000)128<0917: $\mathrm{RCSOHO}>2.0 . \mathrm{CO} ; 2$.

Camargo, S. J., and A. A. Wing, 2016: Tropical cyclones in climate models. Wiley Interdiscip. Rev.: Climate Change, 7, 211-237, https://doi.org/10.1002/wcc.373.

Chen, J.-H., and S.-J. Lin, 2011: The remarkable predictability of inter-annual variability of Atlantic hurricanes during the past decade. Geophys. Res. Lett., 38, L11804, https://doi.org/ 10.1029/2011GL047629.

$\longrightarrow$, and - 2013: Seasonal predictions of tropical cyclones using a $25-\mathrm{km}$-resolution general circulation model. J. Climate, 26, 380-398, https://doi.org/10.1175/JCLI-D-12-00061.1.

Chu, J.-H., C. R. Sampson, A. S. Levine, and E. Fukada, 2002: The Joint Typhoon Warning Center tropical cyclone besttracks, 1945-2000. Naval Research Laboratory Rep. NRL/ MR/7540-02-16, 22 pp.

Colbert, A. J., B. J. Soden, G. A. Vecchi, and B. P. Kirtman, 2013: The impacts of anthropogenic climate change on North Atlantic tropical cyclone tracks. J. Climate, 26, 4088-4095, https:// doi.org/10.1175/JCLI-D-12-00342.1.

Davis, C. A., 2018: Resolving tropical cyclone intensity in models. Geophys. Res. Lett., 45, 2082-2087, https://doi.org/10.1002/ 2017 GL076966.

Delworth, T. L., and Coauthors, 2006: GFDL's CM2 global coupled climate models. Part I: Formulation and simulation characteristics. J. Climate, 19, 643-674, https://doi.org/10.1175/ JCLI3629.1.

—_, and Coauthors, 2012: Simulated climate and climate change in the GFDL CM2.5 high-resolution coupled climate model. J. Climate, 25, 2755-2781, https://doi.org/10.1175/ JCLI-D-11-00316.1.

Emanuel, K., 2006: Climate and tropical cyclone activity: A new model downscaling approach. J. Climate, 19, 4797-4802, https://doi.org/10.1175/JCLI3908.1.

, 2013: Increased global tropical cyclone activity from global warming: Results of downscaling CMIP5 climate models Proc. Natl. Acad. Sci. USA, 110,12219-12 224, https://doi.org/ 10.1073/pnas.1301293110.
2017: Will global warming make hurricane forecasting more difficult? Bull. Amer. Meteor. Soc., 98, 495-501, https://doi.org/ 10.1175/BAMS-D-16-0134.1.

- S. Ravela, E. Vivant, and C. Risi, 2006: A statistical deterministic approach to hurricane risk assessment. Bull. Amer. Meteor. Soc., 87, 299-314, https://doi.org/10.1175/ BAMS-87-3-299.

- K. R. Sundararajan, and J. Williams, 2008: Hurricanes and global warming: Results from downscaling IPCC AR4 simulations. Bull. Amer. Meteor. Soc., 89, 347-367, https://doi.org/ 10.1175/BAMS-89-3-347.

Gnanadesikan, A., and Coauthors, 2006: GFDL's CM2 global coupled climate models. Part II: The baseline ocean simulation. J. Climate, 19, 675-697, https://doi.org/10.1175/ JCLI3630.1.

Harper, B. A., J. D. Kepert, and J. D. Ginger, 2010: Guidelines for converting between various wind averaging periods in tropical cyclone conditions. World Meteorological Organization Tech. Rep. WMO/TD-1555, 54 pp.

Harris, L. M., S.-J. Lin, and C. Tu, 2016: High-resolution climate simulations using GFDL HiRAM with a stretched global grid. J. Climate, 29, 4293-4314, https://doi.org/10.1175/ JCLI-D-15-0389.1.

Holland, G., and C. L. Bruyère, 2014: Recent intense hurricane response to global climate change. Climate Dyn., 42, 617-627, https://doi.org/10.1007/s00382-013-1713-0.

Huang, A., H. Li, R. L. Sriver, A. V. Fedorov, and C. M. Brierley, 2017: Regional variations in the ocean response to tropical cyclones: Ocean mixing versus low cloud suppression. Geophys. Res. Lett., 44, 1947-1955, https://doi.org/10.1002/ 2016GL072023.

Jia, L., and Coauthors, 2015: Improved seasonal prediction of temperature and precipitation over land in a high-resolution GFDL climate model. J. Climate, 28, 2044-2062, https:// doi.org/10.1175/JCLI-D-14-00112.1.

Knapp, K. R., 2008a: Calibration of long-term geostationary infrared observations using HIRS. J. Atmos. Oceanic Technol., 25, 183-195, https://doi.org/10.1175/2007JTECHA910.1. 2008b: Scientific data stewardship of International Satellite Cloud Climatology Project B1 global geostationary observations. J. Appl. Remote Sens., 2, 023548, https://doi.org/10.1117/ 1.3043461 .

— , and J. P. Kossin, 2007: New global tropical cyclone data set from ISCCP B1 geostationary satellite observations. J. Appl. Remote Sens., 1, 013505, https://doi.org/10.1117/1.2712816.

— M. C. Kruk, D. H. Levinson, H. J. Diamond, and C. J. Neumann, 2010: The International Best Track Archive for Climate Stewardship (IBTrACS): Unifying tropical cyclone data. Bull. Amer. Meteor. Soc., 91, 363-376, https://doi.org/ 10.1175/2009BAMS2755.1.

Knutson, T. R., and R. E. Tuleya, 2004: Impact of $\mathrm{CO}_{2}$-induced warming on simulated hurricane intensity and precipitation: Sensitivity to the choice of climate model and convective parameterization. J. Climate, 17, 3477-3495, https://doi.org/ 10.1175/1520-0442(2004)017<3477:IOCWOS >2.0.CO;2.

,-- , and Y. Kurihara, 1998: Simulated increase of hurricane intensities in a $\mathrm{CO}_{2}$-warmed climate. Science, 279, 1018-1020, https://doi.org/10.1126/science.279.5353.1018.

— J J. J. Sirutis, S. T. Garner, I. M. Held, and R. E. Tuleya, 2007: Simulation of the recent multidecadal increase of Atlantic hurricane activity using an 18-km-grid regional model. Bull. Amer. Meteor. Soc., 88, 1549-1565, https://doi.org/10.1175/ BAMS-88-10-1549. 
,,,--- G. A. Vecchi, and I. M. Held, 2008: Simulated reduction in Atlantic hurricane frequency under twenty-firstcentury warming condition. Nat. Geosci., 1, 359-364, https:// doi.org/10.1038/ngeo202.

, and Coauthors, 2010: Tropical cyclones and climate change. Nat. Geosci., 3, 157-163, https://doi.org/10.1038/ngeo779.

— , and Coauthors, 2013: Dynamical downscaling projections of twenty-first-century Atlantic hurricane activity: CMIP3 and CMIP5 model-based scenarios. J. Climate, 26, 6591-6617, https://doi.org/10.1175/JCLI-D-12-00539.1.

— J. J. Sirutis, M. Zhao, R. E. Tuleya, M. Bender, G. A. Vecchi, G. Villarini, and D. Chavas, 2015: Global projections of intense tropical cyclone activity for the late twenty-first century from dynamical downscaling of CMIP5/RCP4.5 scenarios. J. Climate, 28, 7203-7224, https://doi.org/10.1175/JCLI-D-15-0129.1.

Kodama, C., and Coauthors, 2015: A 20-year climatology of a NICAM AMIP-type simulation. J. Meteor. Soc. Japan, 93, 393-424, https://doi.org/10.2151/jmsj.2015-024.

Korty, R. L., K. A. Emanuel, M. Huber, and R. A. Zamora, 2017: Tropical cyclones downscaled from simulations with very high carbon dioxide levels. J. Climate, 30, 649-667, https://doi.org/ 10.1175/JCLI-D-16-0256.1.

Kossin, J. P., 2017: Hurricane intensification along United States coast suppressed during active hurricane periods. Nature, 541, 390-393, https://doi.org/10.1038/nature20783.

— , K. R. Knapp, D. J. Vimont, R. J. Murnane, and B. A. Harper, 2007: A globally consistent reanalysis of hurricane variability and trends. Geophys. Res. Lett., 34, L04815, https://doi.org/ 10.1029/2006GL028836.

_ T. T. Olander, and K. R. Knapp, 2013: Trend analysis with a new global record of tropical cyclone intensity. J. Climate, 26, 9960-9976, https://doi.org/10.1175/JCLI-D-13-00262.1.

Kowch, R., and K. Emanuel, 2015: Are special processes at work in the rapid intensification of tropical cyclones? Mon. Wea. Rev., 143, 878-882, https://doi.org/10.1175/MWR-D-14-00360.1.

Landsea, C. W., and J. L. Franklin, 2013: Atlantic hurricane database uncertainty and presentation of a new database format. Mon. Wea. Rev., 141, 3576-3592, https://doi.org/10.1175/ MWR-D-12-00254.1.

Lee, C.-Y., M. K. Tippett, A. H. Sobel, and S. J. Camargo, 2016: Rapid intensification and the bimodal distribution of tropical cyclone intensity. Nat. Commun., 7, 10625, https://doi.org/ 10.1038/ncomms10625.

Lin, I. I., G. J. Goni, J. A. Knaff, C. Forbes, and M. M. Ali, 2013: Ocean heat content for tropical cyclone intensity forecasting and its impact on storm surge. Nat. Hazards, 66, 1481-1500, https://doi.org/10.1007/s11069-012-0214-5.

Liu, M., G. A. Vecchi, J. A. Smith, and H. Murakami, 2017: The present-day simulation and twenty-first-century projection of the climatology of extratropical transition in the North Atlantic. J. Climate, 30, 2739-2756, https://doi.org/ 10.1175/JCLI-D-16-0352.1.

Lloyd, I. D., and G. A. Vecchi, 2011: Observational evidence for oceanic controls on hurricane intensity. J. Climate, 24, 11381153, https://doi.org/10.1175/2010JCLI3763.1.

Manganello, J. V., and Coauthors, 2012: Tropical cyclone climatology in a 10-km global atmospheric GCM: Toward weatherresolving climate modeling. J. Climate, 25, 3867-3893, https:// doi.org/10.1175/JCLI-D-11-00346.1.

, and Coauthors, 2014: Future changes in the western North Pacific tropical cyclone activity projected by a multidecadal simulation with a 16-km global atmospheric GCM. J. Climate, 27, 7622-7646, https://doi.org/10.1175/JCLI-D-13-00678.1.
McClean, J. L., and Coauthors, 2011: A prototype two-decade fully-coupled fine-resolution CCSM simulation. Ocean Modell., 39, 10-30, https://doi.org/10.1016/j.ocemod.2011.02.011.

Murakami, H., and B. Wang, 2010: Future change of North Atlantic tropical cyclone tracks: Projection by a $20-\mathrm{km}-\mathrm{mesh}$ global atmospheric model. J. Climate, 23, 2699-2721, https:// doi.org/10.1175/2010JCLI3338.1.

, and Coauthors, 2012: Future changes in tropical cyclone activity projected by the new high-resolution MRI-AGCM. J. Climate, 25, 3237-3260, https://doi.org/10.1175/JCLI-D-11-00415.1.

_ B. Bang, T. Li, and A. Kitoh, 2013: Projected increase in tropical cyclones near Hawaii. Nat. Climate Change, 3, 749754, https://doi.org/10.1038/nclimate1890.

_ , and Coauthors, 2015: Simulation and prediction of category 4 and 5 hurricanes in the high-resolution GFDL HiFLOR coupled climate model. J. Climate, 28, 9058-9079, https://doi.org/ 10.1175/JCLI-D-15-0216.1.

_ and landfalling tropical cyclones using a high-resolution GFDL coupled climate model. J. Climate, 29, 7977-7989, https://doi.org/10.1175/JCLI-D-16-0233.1.

Olander, T. L., and C. S. Velden, 2007: The advanced Dvorak technique: Continued development of an objective scheme to estimate tropical cyclone intensity using geostationary infrared satellite imagery. Wea. Forecasting, 22, 287-298, https:// doi.org/10.1175/WAF975.1.

Oouchi, K., J. Yoshimura, H. Yoshimura, R. Mizuta, S. Kusunoki, and A. Noda, 2006: Tropical cyclone climatology in a globalwarming climate as simulated in a $20 \mathrm{~km}$-mesh global atmospheric model: Frequency and wind intensity analysis. J. Meteor. Soc. Japan, 84, 259-276, https://doi.org/10.2151/jmsj.84.259.

Pielke, R. A., Jr., J. Gratz, C. W. Landsea, D. Collins, M. Saunders, and R. Musulin, 2008: Normalized hurricane damages in the United States: 1900-2005. Nat. Hazards Rev., 9, 29-42, https:// doi.org/10.1061/(ASCE)1527-6988(2008)9:1(29).

Rathmann, N. M., S. Yang, and E. Kaas, 2014: Tropical cyclones in enhanced resolution CMIP5 experiments. Climate Dyn., $\mathbf{4 2}$, 665-681, https://doi.org/10.1007/s00382-013-1818-5.

Rayner, N. A., D. E. Parker, E. B. Horton, C. K. Folland, L. V. Alexander, D. P. Rowell, E. C. Kent, and A. Kaplan, 2003: Global analyses of sea surface temperature, sea ice, and night marine air temperature since the late nineteenth century. J. Geophys. Res., 108, 4407, https://doi.org/10.1029/2002JD002670.

Schade, L. R., and K. A. Emanuel, 1999: The ocean's effect on the intensity of tropical cyclones: Results from a simple coupled atmosphere-ocean model. J. Atmos. Sci., 56, 642-651, https:/ doi.org/10.1175/1520-0469(1999)056<0642:TOSEOT>2.0.CO;2.

Scoccimarro, E., P. G. Fogli, K. A. Reed, S. Gualdi, S. Masina, and A. Navarra, 2017: Tropical cyclone interaction with the ocean: The Role of high-frequency (subdaily) coupled processes. J. Climate, 30, 145-162, https://doi.org/10.1175/ JCLI-D-16-0292.1.

Shaevitz, D. A., and Coauthors, 2014: Characteristics of tropical cyclones in high-resolution models in the present climate. J. Adv. Model. Earth Syst., 6, 1154-1172, https://doi.org/10.1002/ 2014MS000372.

Small, R. J., and Coauthors, 2014: A new synoptic scale resolving global climate simulation using the Community Earth System Model. J. Adv. Model. Earth Syst., 6, 1065-1094, https:// doi.org/10.1002/2014MS000363.

Suissa, S., and J. J. Shuster, 1985: Exact unconditional sample sizes for the $2 \times 2$ binomial trial. J. Roy. Stat. Soc., 148A, 317-327, https://doi.org/10.2307/2981892. 
Takagi, H., and M. Esteban, 2016: Statistics of tropical cyclone landfalls in the Philippines: Unusual characteristics of 2013 Typhoon Haiyan. Nat. Hazards, 80, 211-222, https://doi.org/ 10.1007/s11069-015-1965-6.

Uhlhorn, E. W., and D. S. Nolan, 2012: Observational undersampling in tropical cyclones and implications for estimated intensity. Mon. Wea. Rev., 140, 825-840, https://doi.org/10.1175/ MWR-D-11-00073.1.

_- P. G. Black, J. L. Franklin, M. Goodberlet, J. Carswell, and A. S. Goldstein, 2007: Hurricane surface wind measurements from an operational stepped frequency microwave radiometer. Mon. Wea. Rev., 135, 3070-3085, https://doi.org/10.1175/ MWR3454.1.

van der Wiel, K., S. B. Kapnick, and G. A. Vecchi, 2017: Shifting patterns of mild weather in response to projected radiative forcing. Climatic Change, 140, 649-658, https://doi.org/ 10.1007/s10584-016-1885-9.

Van Vuuren, D. P., and Coauthors, 2011: The representative concentration pathways: An overview. Climatic Change, 109, 5-31, https://doi.org/10.1007/s10584-011-0148-z.

Vecchi, G. A., and Coauthors, 2014: On the seasonal forecasting of regional tropical cyclone activity. J. Climate, 27, 7994-8016, https://doi.org/10.1175/JCLI-D-14-00158.1.

Walsh, K. J. E., and Coauthors, 2015: Hurricanes and climate: The U.S. CLIVAR Working Group on hurricanes. Bull. Amer. Meteor. Soc., 96, 997-1017, https://doi.org/10.1175/ BAMS-D-13-00242.1.

_- and Coauthors, 2016: Tropical cyclones and climate change. Wiley Interdiscip. Rev.: Climate Change, 7, 65-89, https://doi.org/ 10.1002/wcc.371.

Wehner, M., Prabhat, K. A. Reed, D. Stone, W. D. Collins, and J. Bacmeister, 2015: Resolution dependence of future tropical cyclone projections of CAM5.1 in the U.S. CLIVAR Hurricane
Working Group idealized configurations. J. Climate, 28, 39053925, https://doi.org/10.1175/JCLI-D-14-00311.1.

Wilks, D. S., 2011: Statistical Methods in the Atmospheric Sciences. 3rd ed. International Geophysics Series, Vol. 100, Academic Press, 676 pp.

Wittenberg, A. T., A. Rosati, N. Lau, and J. J. Ploshay, 2006: GFDL's CM2 global coupled climate models. Part III: Tropical Pacific climate and ENSO. J. Climate, 19, 698-722, https:// doi.org/10.1175/JCLI3631.1.

Yamada, Y., K. Oouchi, M. Satoh, H. Tomita, and W. Yanase, 2010: Projection of changes in tropical cyclone activity and cloud height due to greenhouse warming: Global cloudsystem-resolving approach. Geophys. Res. Lett., 37, L07709, https://doi.org/10.1029/2010GL042518.

—, M. Satoh, M. Sugi, C. Kodama, A. T. Noda, M. Nakano, and T. Nasuno, 2017: Response of tropical cyclone activity and structure to global warming in a high-resolution global nonhydrostatic model. J. Climate, 30, 9703-9724, https://doi.org/ 10.1175/JCLI-D-17-0068.1.

Zhang, L., K. B. Karnauskas, J. P. Donnelly, and K. Emanuel, 2017: Response of the North Pacific tropical cyclone climatology to global warming: Application of dynamical downscaling to CMIP5 models. J. Climate, 30, 1233-1243, https://doi.org/ 10.1175/JCLI-D-16-0496.1.

Zhang, W., and Coauthors, 2016: Improved simulation of tropical cyclone responses to ENSO in the western North Pacific in the high-resolution GFDL HiFLOR coupled climate model. J. Climate, 29, 1391-1415, https://doi.org/10.1175/ JCLI-D-15-0475.1.

Zhao, M., I. M. Held, S.-J. Lin, and G. A. Vecchi, 2009: Simulations of global hurricane climatology, interannual variability, and response to global warming using a $50-\mathrm{km}$ resolution GCM. J. Climate, 22, 6653-6678, https://doi.org/10.1175/2009JCLI3049.1. 